\title{
Normatividad urbanística virtual en la Ciudad de México*
}

\author{
Gustavo Garza \\ El Colegio de México \\ Centro de Estudios Demográficos y \\ de Desarrollo Urbano \\ Camino al Ajusco No. 20 \\ Pedregal de Santa Teresa \\ 01000 México, D.F.
}

Tel. (5) 6454459

Fax (5) 6450464

El Área Metropolitana de la Ciudad de México (AMCM) es la cuarta ciudad más poblada del mundo, después de Tokio, Nueva York y São Paulo. En 1990 está constituida por un tejido urbano relativamente continuo que tiene como centro la Plaza de la Constitución (Zócalo), y se extiende en las 16 delegaciones en que se divide políticamente el Distrito Federal y en 32 municipios del Estado de México, en una exrensión de $1,706 \mathrm{~km}^{2}$. Es práctica común referirse al AMCM como la Ciudad de México, el Distrito Federal y la capital, dado que no existe una definición política sobre el área metropolitana en su conjunto'.

- Agradezcola importante asistencia de Gabriela Grajales durante la realización de todo el trabajo.

1 Hasta 1970 el Dimito Federal se subdividía políticamente en 12 cuarteles y 12 delegaciones. A los cuarteles se les denominaba Ciudad de México, por lo que a ellos se referín políticamente esta expresión. La Ley Orgánica del 29 de diciembre de 1970 desaparece los cuarteles y los transforma en cuatro delegaciones, constituyéndose el Distrito Federal por 16 delegaciones. En la Iey Orgánica de 1970 y en su revisión de 1973 se señalaba en su artículo 1: "El Dimito Federal o Ciudad de México ...", haciendo equivalentes ambas expresiones. En la Iey Orgánica de 1983 se eliminan las palabras Ciudad de México, por lo que políticamente sólo existe el Distrito Federal y sus delegaciones y el Estado de México con sus municipios. El primero de agosto de 1994 se decreta el Estatuto de Gobierno del Distrito Federal, que en su capítulo dos señala: 'La Ciudad de México es el Distrito Federal sede de los Poderes de la Unión y Capital de los Estados Unidos Mexicanos". Esto define a la Ciudad de México como la parte de su área urbana ubicada dentro de los límites del Distrito Federal, sentenciando al resto de la ciudad real a no ser Ciudad de México. El Área Metropolitana de la Ciudad de México en Su conjunto tiene pues una extensión virtual, esto es, una existencia práctica aludiendo a una de las acepciones de este adjetivo. El área o zona metropolitana de la Ciudad de México para 1990 aquí considerada no ha sido técnicamente delimitada, 
De esta suerte, desde el punto de vista legal la Ciudad de México es la parte del AMCM que se ubica en el Distrito Federal, pero en su carácter de área metropolitana constituye la más colosal obra realizada en toda la historia de la nación.

El objetivo central de este trabajo es presentar una imagen totalizadora del cuerpo de normas urbanísticas vigente en la actualidad en el Distrito Federal que rigen su expansión urbana. Específicamente se tienen tres propósitos concretos: $i$ ) describir las peculiaridades demográficas y urbanísticas del Área Metropolitana de la Ciudad de México subdividida en la parte correspondiente al Distrito Federal y la del Estado de México; ií) esquematizar las características básicas de las leyes, reglamentos y programas vigentes exclusivamente en el Distrito Federal, enfatizando aquellas que determinan más directamente la forma de su estructura urbana; y, iii) reflexionar sobre las perspectivas del desarrollo urbano del Distrito Federal y la adecuación de su normatividad urbanística.

\section{Evolución demográfica y urbanística}

Fundada en 1522 por Hernán Cortés, la Ciudad de México fue la localidad más importante de la Nueva España, aunque su crecimiento desde el siglo XVI a inicios del XIX fue muy lento: los 30 mil habitantes existentes al momento de su fundación se elevan a 180 mil en 1810, año en que se inicia la Guerra de Independencia. Durante todo el siglo XIX únicamente logra duplicar su población al alcanzar en 1900 una población de 344 mil habitantes.

Una vez que se estabiliza el país, hacia principios de los años treinta en el periodo posrevolucionario, la Ciudad de México inicia una acelerada transformación económica, demográfica y urbanística que la convertiría en una de las metrópolis más grandes del mundo. En 1930 alcanza un millón de habitantes, que aumentan a 3.1 en 1950, año en que principia su expansión metropolitana al extender su crecimiento hacia el municipio de Tlalnepantla, en el Estado de México. Para 1960 una dinámica Área Metropolitana de la Ciudad de México (AMCM) eleva su población a 5.4 millones de habitantes incorporando a los municipios de Naucalpan, Chimalhuacán y

utilizéndose la adoptada por Garza y Rivera (1995), que consideran 27 municipios conurbados del Estado de Mścico, más los siguientes 5 municipios que se incorporan entre 1980-1990 según información de la Dirección General de Planificación del Estado de México: Isidro Fabela, Jaltenco, Jilotzingo, Nextlalpan y Teotihuacín.

Ecatepec, con lo que absorbe cuatro municipios conurbados del Estado de México.

A partir de los años sesenta la expansión del AMCM se acelera notablemente. En 1970 alcanza 87 millones de habitantes, los cuales se distribuyen en 6.9 en el Distrito Federal y 1.8 en 11 municipios conurbados del Estado de México. En 1980 su población total se eleva a 12.8 millones de habitantes, aumentando entre 19701980 a una tasa de $3.9 \%$ anual, siendo ésta de $1.9 \%$ en el Distrito Federal y de $9.4 \%$ en los 17 municipios conurbados del Estado de México (véase el cuadro 1).

En 1990 el AMCM esta constituida por 15.8 millones de habitantes, divididos en 8.6 millones en el Distrito Federal y 7.2 millones en 32 municipalidades mexiquenses (véase el cuadro 1). La tasa de crecimiento anual entre 1980-1990 se reduce notablemente a 2.1\%, siendo de únicamente 0.390 en el Distrito Federal y de $4.8 \%$ en los municipios conurbados. Según la información preliminar del conteo de población y vivienda de 1995, el AMCM, según se ha definido en este trabajo, tiene 17.0 millones de habitantes, subdivididos en 8.8 en el Distrito Federal y 8.2 en los 32 municipios conurbados del Estado de México (véase el cuadro 1). El Distrito Federal se mantiene como la parte con mayor población de la metrópoli, aunque entre 1990-1995 presenta una tasa de crecimiento anual de $0.56 \%$, considerablemente menor que el $2.69 \%$ de 105 municipios conurbados mexiquenses.

Los 17 millones de habitantes del AMCM en 1995 se encuentran distribuidos en partes muy semejantes en el Distrito Federal y en los 32 municipios conurbados del Estado de México. Estas dos entidades federativas cuentan con estructuras jurídicopolíticas y normas urbanísticas diferentes, siendo que la urbe se encuentra gobernada por un Regente nombrado por el Presidente de la República (que a partir de 1997 será electo por la población), un Gobernador electo del Estado de México, 16 Delegados nombrados por el Regente y 32 Presidentes municipales electos.

A este conjunto de instancias administrativas se aplican dos cuerpos diferentes de normas y políticas urbanísticas que rigen la expansión de las áreas urbanas correspondientes. En este contexto, el objetivo central del artículo es presentar una imagen totalizadora del complejo conjunto de leyes, decretos, normas, reglamentos y planes vigentes que rigen el desarrollo urbanístico de la Ciudad de México, con la finalidad de que a partir de una visión amplia de su intrincada superestructura normativa sea factible diseñar un código 
Cuadro 1

Población total del AMCM, 1970-1990 2

\begin{tabular}{|c|c|c|c|c|c|c|}
\hline \multirow[b]{2}{*}{ UNDOAD ADMINISTRATNNA } & \multicolumn{3}{|c|}{ POBLACOON } & \multicolumn{3}{|c|}{ TASA DE CRECIMENTIO } \\
\hline & 1970 & 1980 & 1990 & $\overline{1970-1980}$ & $1980-1990$ & $1970-1990$ \\
\hline $\begin{array}{l}\text { TOTAL } \\
\text { AREA METROPOITTANA }\end{array}$ & 8752968 & 12860374 & 15782943 & 3.92 & 2.07 & 2.99 \\
\hline DISTRTO FEDERAL & 6914014 & 8360193 & 8579375 & 1.22 & 0.26 & 1.08 \\
\hline 1. Alvaro Obregon & 523461 & 604643 & 671395 & 1.45 & 1.05 & 1.25 \\
\hline $\begin{array}{l}\text { 2. Azocpostzateo } \\
\text { 3. Benito Juarez }\end{array}$ & $\begin{array}{l}535890 \\
590750\end{array}$ & $\begin{array}{l}51404 \\
51404\end{array}$ & 421520 & $\begin{array}{c}0.37 \\
-1.37\end{array}$ & $\begin{array}{l}-1.44 \\
-1.97\end{array}$ & $\begin{array}{l}-1.67 \\
-1.67\end{array}$ \\
\hline 4. Coyoacán & 346520 & 566252 & 669989 & 5.03 & 1.68 & 3.34 \\
\hline 5. Cuarimalpa & 37498 & 86725 & 125922 & 8.75 & 3.8 & 6.24 \\
\hline 6. Duauhtémoc & 929418 & & $\begin{array}{r}615692 \\
\end{array}$ & -1.88 & -2.2 & -2.04 \\
\hline $\begin{array}{l}\text { 7. Gustavo A. Madero } \\
\text { 8. Iztacico }\end{array}$ & $\begin{aligned} & 195145 \\
& 479692\end{aligned}$ & $\begin{array}{r}1431919 \\
539476\end{array}$ & $\begin{aligned} 1315572 \\
466220\end{aligned}$ & $\begin{array}{l}1.82 \\
1.18\end{array}$ & $\begin{array}{l}-0.84 \\
-1.49 \\
-1\end{array}$ & $\begin{array}{r}0.48 \\
-0.16\end{array}$ \\
\hline 9. Izapalapa & 539998 & 1199582 & 1563159 & 8.31 & 2.68 & 5.46 \\
\hline 10. Magdalena Contreras & $\pi 838$ & 164558 & & 7.77 & 2.18 & 4.94 \\
\hline 11. Migued Hidaligo & 586537 & 512756 & 420456 & -1.34 & -1.97 & -1.65 \\
\hline 12. Mipa & 34256 & 50788 & 66659 & 4.02 & 2.76 & 3.38 \\
\hline 13. Tláhus & $644 \pi$ & 139595 & 217860 & 8.03 & 4.55 & 6.28 \\
\hline 14. Tlalp & 136027 & $\begin{array}{l}350934 \\
65460\end{array}$ & $\begin{array}{c}510201 \\
537213\end{array}$ & 9.994 & $\begin{array}{r}3.81 \\
-1.95\end{array}$ & $\begin{array}{r}6.83 \\
-144\end{array}$ \\
\hline $\begin{array}{l}\text { 15. Venustiano Carranza } \\
\text { 16. Xochimitoo }\end{array}$ & $\begin{array}{l}711697 \\
119210\end{array}$ & $\begin{array}{l}6553600 \\
206402\end{array}$ & $\begin{array}{l}537213 \\
284604\end{array}$ & $\begin{array}{l}-0.92 \\
5.64\end{array}$ & $\begin{array}{l}-1.95 \\
-3.26\end{array}$ & $\begin{array}{l}-1.44 \\
-4.45\end{array}$ \\
\hline ESTADO DE MEXTCO & 1838654 & 4500181 & 7203568 & 9.36 & 4.82 & 7.07 \\
\hline 1. Alizióñ de Zaragoza & 46964. & 186 & 333872 & 14.78 & $6 . \mathrm{c}$ & 10.3 \\
\hline 2. Coacal & 14259 & & & & & 12.9 \\
\hline 3. Caaut & 40937 & & & 26 & 1 & 1.14 \\
\hline 4. Chim & 20005 & & & 56 & 16.57 & 13.52 \\
\hline & 22177 & 7219 & 1290449 & 12.26 & 5.98 & \\
\hline 6. the & 34570 & 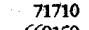 & & & 6.93 & 7.25 \\
\hline & & 669159 & & & 2.09 & 3.79 \\
\hline 8. Neze & 598286 & 1230604 & 131 ? & & 0.65 & 4.01 \\
\hline 9. $\mathrm{L}_{2}$ & 33641 & & & 10.52 & 4.4 & 7.41 \\
\hline anta & 376996 & & & 6.59 & 0.25 & 3.337 \\
\hline 11. Tulat & 54198 & 125643 & & 8.77 & 7.57 & 8.17 \\
\hline 12. Ch & & & & & $\begin{array}{l}15.65 \\
0.24\end{array}$ & \\
\hline 13. Ch & & & & & 9.24 & \\
\hline $\begin{array}{l}\text { Ca } \\
\text { Romero }\end{array}$ & & $\begin{array}{l}1032901 \\
1030\end{array}$ & 195420 & & $\begin{array}{l}7.43 \\
6.58\end{array}$ & \\
\hline 16. $\mathrm{Ter}$ & & 7732 & & & 534 & \\
\hline in lzcalli & & 157717 & 347751 & & 8.23 & \\
\hline 18. Ac & & & & & & \\
\hline $\begin{array}{l}\text { 19. Aten } \\
\text { 20. Chiat }\end{array}$ & & & & & & \\
\hline & & & 14763 & & & \\
\hline & & & 5516 & & & \\
\hline 23. Jalten & & & 24608 & & & \\
\hline 24. Jil & & & 9511 & & & \\
\hline 25. Melc & & & & & & \\
\hline $\begin{array}{l}\text { 26. } \mathrm{N} \text { - } \\
\text { 27. }\end{array}$ & & & & & & \\
\hline 28. Tea & & & 32 & & & \\
\hline 29. Tepc & & & 42 & & & \\
\hline 30. Tex & & & & & & \\
\hline 31. Tezoyuca & & & 13134 & & & \\
\hline
\end{tabular}

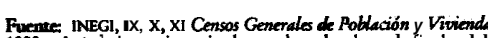

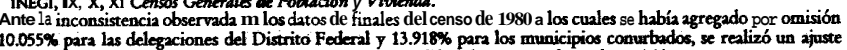

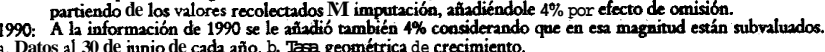

urbano que los articule y coordine, asimismo que las uniforme, en forma de una reglamentación metropolitana única.

Antes de ello será conveniente describir la expansión del tejido o mancha urbana del AMCM, que constituye la base donde se aplica la normatividad urbanística existente. La información de la superficie del tejido urbano es de diversas estimaciones y no es del todo comparable, pero es útil para tener una idea aceptable de su extensión y densidad de población.

En 1900, al inicio del siglo xx, Ia Ciudad de México era una localidad de tamaño relativamente pequeño; con 345 mil habitantes distribuidos en 2,714 hectáreas, estimándose un densidad de 127 habitantes por hectárea (hab/ha). A mediados del siglo, la urbe constituía una metrópoli de considerable tamaño al tener 2.3 millones de habitantes que presentaban un densidad de $99 \mathrm{hab} / \mathrm{ha}$. Entre 1950-1970 el AMCM creció a una tasa anual de $\mathbf{6 . 9 \%}$, alcanzando 8.8 millones de habitantes en 1970 y una densidad de 128 hab/ha, la más elevada hasta la actualidad (véase el cuadro 2). En los siguientes 20 años su tasa de crecimiento se reduce a 3.0\% anual y su densidad en 1990 es de $93 \mathrm{hab} / \mathrm{ha}$, siendo la menor registrada desde 1900. Esto resulta de su expansión física hacia los municipios periféricos del Estado de México, que presentan una baja densidad. Efectivamente, las densidades de población entre las diferentes delegaciones y municipios del AMCM presentan considerables diferencias. En general, el área urbana del Distrito Federal es más densa que la de los municipios conurbados, siendo en la primera de $110 \mathrm{hab} / \mathrm{ha}$ y en los segundos de $78 \mathrm{hab} / \mathrm{ha}$ (véase el cuadro 3).

Cuadro 2

AMCM: Extensión del tejido urbano y

densidad de población, 1900-1990

\begin{tabular}{|cccr|}
\hline Año & $\begin{array}{c}\text { Tas } \\
\text { turbano } \\
\text { (bas) }\end{array}$ & $\begin{array}{c}\text { Población } \\
\text { Dotal }\end{array}$ & $\begin{array}{r}\text { Densidad } \\
\text { (babha) }\end{array}$ \\
\hline 1900 & 2714 & 344721 & 127 \\
1950 & 22989 & 2287000 & 99 \\
1960 & 47070 & 4910000 & 104 \\
1970 & 68260 & 8752168 & 128 \\
1980 & 107973 & 12560374 & 119 \\
1990 & 170572 & 15782943 & 93 \\
\hline
\end{tabular}

Fuente: Información del teiido urbano para $1900-1980$ del Departamento de

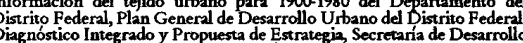

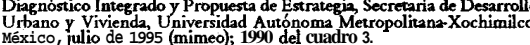


Al interior del Distrito Federal, sin embargo, existen también diferencias muy acentuadas. En un extremo se encuentra el área urbana de Milpa Alta con 25 hab/ha, y en el otro Iztacalco con $203 \mathrm{hab} / \mathrm{ha}$ (véase el cuadro 3). En los municipios conurbados se tiene en un extremo a Isidro Fabela con $15 \mathrm{hab} / \mathrm{ha}$, y en otro a Nezahualcóyotl con $261 \mathrm{hab} / \mathrm{ha}$, que es la unidad administrativadel AMCM más densamente poblada (véase el cuadro 3).

En síntesis, en 1990 el AMCM tiene una superficie urbanizada de 170,572 hectáreas donde habitan 15.8 millones de personas, presentando acusadas diferencias de densidades en las 16 delegaciones y los 32 municipios donde se localiza (véase el cuadro 3). La superficie territorial total de estas 48 unidades administrativas es de 4,981 kilómetros cuadrados, por lo que el tejido urbano sólo representa $34.2 \%$ de dicho total, constituyendo la diferencia un territorio envolvente de la mancha urbana, esto es, parte de una zona metropolitana que no fue posible delimitar con precisión.

En lo que sigue se presenta el marco normativo del Distrito Federal, que intenta regular a este gran conglomerado urbano que constituye la más compleja y colosal obra realizada en toda la historia de la nación.

Distrito Federal: leyes, decretos, acuerdos, normas, reglamentos Y programas

En 1928 se crea por decreto presidencial el Departamento del Distrito Federal, suprimiendo las antiguas municipalidades que formaban la Ciudad de México y el Distrito Federal. Desde los años treinta, por tanto, se ha establecido un conjunto de leyes, decretos, programas, normas y reglamentos que constituyen la estructura jurídica que lo regula. Para los propósitos del presente trabajo interesa describir el conjunto de normas vigentes que rigen la estructura y dinámica urbana de la parte del Área Metropolitana de la Ciudad de México ubicada en el Distrito Federal. Antes de ello sin embargo, es necesario bosquejar las características básicas de su gobierno.

Hasta 1996 el presidente de la República designa a un Jefe del Departamento, o Regente, quien gobierna la ciudad y nombra a 16 delegados para otras tantas entidades en que ésta se encuentra políticamente dividida. En los últimos años, en el transcurso de las luchas políticas por lograr la democratización del gobierno del Distrito Federal, se han establecido instancias más representativas de

Cuadro 3

AMCM: Superficie total, urbana y densidad de población, 1990

\begin{tabular}{|c|c|c|c|c|c|c|}
\hline UNDDAD ADMENDIRATNA & $\begin{array}{l}\text { AREA } \\
\text { TOTALA } \\
\left({ }^{2} m^{*}\right)\end{array}$ & $\%$ & $\begin{array}{c}\text { AREA } \\
\text { URRANA } \\
\left(\mathrm{km}^{2}\right) \\
\end{array}$ & $\%$ & POBLACTÓN & $\begin{array}{l}\text { DENEDADAD } \\
\text { URBANA } \\
\text { (bahba) }\end{array}$ \\
\hline TOTAL & 4980.79 & 100.00 & 1705.72 & 34.20 & 15782943 & 92.53 \\
\hline DISTRTTO FEDERAL & 1489.36 & 100.00 & 778.62 & 52.30 & 8579375 & 110.19 \\
\hline 1. Alvaro Obregon & 7.20 & 100.00 & $\pi 7.20$ & 100.00 & 671395 & 86.97 \\
\hline $\begin{array}{l}\text { 2. Azcapuzalo } \\
\text { 3. Benito Juán }\end{array}$ & $\begin{array}{l}33.30 \\
26.63\end{array}$ & $\begin{array}{l}100.00 \\
100.00\end{array}$ & $\begin{array}{l}33.30 \\
26.63\end{array}$ & $\begin{array}{l}100.00 \\
100.00\end{array}$ & $\begin{array}{l}491773 \\
421520\end{array}$ & $\begin{array}{l}147.68 \\
15820\end{array}-10$ \\
\hline 4. coyoacán & 53.89 & 100.00 & 53.89 & $\begin{array}{l}100.00 \\
1000\end{array}$ & $\begin{array}{l}8211200 \\
669989\end{array}$ & $\begin{array}{l}158.29 \\
12.414\end{array}-3$ \\
\hline 5. Cuajimalpa & 80.95 & 100.00 & 28.65 & 35.40 & 125922 & $\begin{array}{l}12.419 \\
43.95\end{array}$ \\
\hline 6. Cuauhtérioc & 32.44 & 100.00 & 32.43 & 100.00 & 615692 & 189.85 \\
\hline 7. Gustavo A. Madero & 86.62 & 100.00 & 86.62 & 100.00 & 1315572 & 151.88 \\
\hline 8. Iztacalco & 22.90 & 100.00 & 22.90 & 100.00 & 464220 & 202.72 \\
\hline & $\begin{array}{l}115.06 \\
75.36\end{array}$ & 100.00 & 113.74 & 98.90 & 1563159 & 137.43 \\
\hline $\begin{array}{l}\text { Ena Contreras } \\
\text { Hidalgo }\end{array}$ & $\begin{array}{l}75.36 \\
46.40\end{array}$ & 100.00 & 19.20 & $\begin{array}{r}25.50 \\
10000\end{array}-10$ & 204138 & 106.32 \\
\hline $\begin{array}{l}\text { 11. Miguel Hidalgo } \\
\text { 12. Milpa Atra }\end{array}$ & $\begin{array}{r}46.40 \\
283.75\end{array}$ & $\begin{array}{l}100.00 \\
100.00\end{array}$ & $\begin{array}{l}46.40 \\
26.35\end{array}$ & $\begin{array}{c}100.00 \\
9.30\end{array}$ & $\begin{array}{r}420456 \\
6659\end{array}$ & $\begin{array}{l}90.62 \\
2530\end{array}$ \\
\hline 13. Tlahuac & 91.78 & 100.00 & 35.77 & $\begin{array}{r}9.30 \\
39.00\end{array}$ & $\begin{array}{r}66659 \\
217860\end{array}$ & $\begin{array}{l}25.30 \\
60.91\end{array}$ \\
\hline 14. Thalyan & 304.49 & 100.00 & 82.83 & 27.20 & 510201 & $\begin{array}{l}60.91 \\
61.60\end{array}$ \\
\hline $\begin{array}{l}\text { 15. Venustiano Carranza } \\
\text { 16. Xohimilco }\end{array}$ & $\begin{array}{r}33.42 \\
125.17\end{array}$ & $\begin{array}{l}100.00 \\
100.00\end{array}$ & $\begin{array}{c}33.42 \\
\leqslant 920\end{array}$ & 100.00 & 537213 & $\begin{array}{r}160.75 \\
8000\end{array}$ \\
\hline 16.Xochimilco & 125.17 & 100.00 & 59.29 & 47.40 & 284604 & 48.00 \\
\hline ESTADO DE MEXTCO & 3491.43 & 100.00 & 927.10 & 26.60 & 7203568 & 77.70 \\
\hline $\begin{array}{l}\text { 1. Aoolman } \\
\text { 2. Atenco }\end{array}$ & $\begin{array}{l}86.88 \\
94.67\end{array}$ & $\begin{array}{l}100.00 \\
100.00\end{array}$ & $\begin{array}{r}20.60 \\
2.09\end{array}$ & $\begin{array}{r}23.70 \\
2.20\end{array}$ & $\begin{array}{l}45655 \\
22247\end{array}$ & $\begin{array}{r}22.16 \\
.046\end{array}$ \\
\hline 3. Alizzapán de Zaragoza & 299.88 & 100.00 & 64.83 & 72.10 & $\begin{array}{r}22247 \\
333872\end{array}$ & $\begin{array}{r}106.44 \\
51.50\end{array}$ \\
\hline 4. Cha & 274.43 & 100.00 & 51.83 & 18.90 & 307468 & 59.32 \\
\hline & 155.49 & & 3.72 & 2.40 & 15598 & 41.93 \\
\hline & & & & 13.90 & & 71.91 \\
\hline $\begin{array}{l}\text { 7. Chic } \\
\text { 8. Chin }\end{array}$ & & & 30 & $\begin{array}{r}5.20 \\
65.30\end{array}$ & 14763 & 40.78 \\
\hline $\begin{array}{l}\text { 8. Chimalhuacín } \\
\text { 9. Coacalco }\end{array}$ & 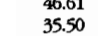 & & 17.17 & $\begin{array}{l}65.30 \\
48.40\end{array}$ & $\begin{array}{l}263010 \\
161410\end{array}$ & $\begin{array}{l}86.46 \\
9401\end{array}$ \\
\hline 10. Cuatidán & 109.92 & & 76 & 69.10 & $\begin{array}{l}101410 \\
34751\end{array}$ & $\begin{array}{l}94.01 \\
45.76\end{array}$ \\
\hline in licalli & & & & 20.40 & $\begin{array}{l}3471393 \\
51393\end{array}$ & 年 45.76 \\
\hline & & & 118 & 76.50 & 1290449 & 108.48 \\
\hline & & & 23 & 16.20 & 140116 & 60.21 \\
\hline & & & & 5.40 & & 15.32 \\
\hline $\begin{array}{l}\text { 15. Ixtapaluca } \\
\text { 16.Jaltenco }\end{array}$ & 31 & & $\begin{array}{c}28 . \\
5 .\end{array}$ & 6560 & $\begin{array}{l}146113 \\
2608\end{array}$ & .47 \\
\hline 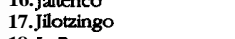 & $\begin{array}{ll}12 \\
117\end{array}$ & & 0. & $\begin{array}{r}\begin{array}{r}45.60 \\
0.60\end{array} \\
\end{array}$ & 24608 & $\begin{array}{r}43.25 \\
132.10\end{array}$ \\
\hline & & & 24. & 89.60 & $\begin{array}{l}5511 \\
140579\end{array}$ & $\begin{array}{r}132.10 \\
57.59\end{array}$ \\
\hline campo & & & & 41.50 & 27646 & $\begin{array}{l}57.59 \\
43.88\end{array}$ \\
\hline & & & 74 & 50.00 & & $\begin{array}{l}43096 \\
109.69\end{array}$ \\
\hline & & & 7 & 0 & & 15.60 \\
\hline 22.1 & & & & 79.30 & & 260.81 \\
\hline 24. & 153 & & & $\begin{array}{l}{ }_{28.00}^{6.00} \\
\end{array}$ & & $\begin{array}{l}52.29 \\
30.29\end{array}$ \\
\hline & & & 1 & $\begin{array}{l}28.00 \\
44.50\end{array}$ & 130 & $\begin{array}{l}30.29 \\
31.60\end{array}$ \\
\hline & & & & 12.90 & & $\begin{array}{l}31.60 \\
30.41\end{array}$ \\
\hline & & & & & & 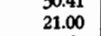 \\
\hline B. Texcoco & 418. & & 46. & 1 & 3 & 31.68 \\
\hline 29. Tezsуuса & 10 & 100.00 & 6.4 & 40.50 & 13154 & 29.83 \\
\hline 30. Talnepanda & $\begin{array}{l}83.4 \\
22.4\end{array}$ & 100.00 & 67.6 & $\begin{array}{l}81.00 \\
570\end{array}$ & 731939 & 108.21 \\
\hline 32. Tultidán & 71.09 & 100.00 & $\begin{array}{l}22.30 \\
36.73\end{array}$ & $\begin{array}{l}\begin{array}{r}54.70 \\
51.70\end{array} \\
\end{array}$ & 260598 & 70.95 \\
\hline
\end{tabular}

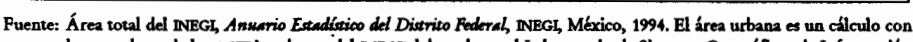

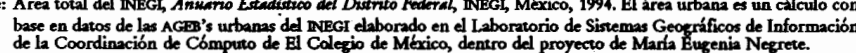


la población, como el caso de la Asamblea de Representantes, creada en 1988 con miembros electos de los diversos partidos políticos. En 1993 se aprobó en el Congreso de la Unión una reforma política para elegir en 1997 al Regente mediante una terna de miembros del partido con más votos, de entre los cuales el Presidente nombraría a uno y lo sometería a la Asamblea de Representantes para su ratificación. Este cambio no fue satisfactorio para los partidos políticos, que siguieron discutiendo sobre la reforma electoral durante 1995 y la primera mitad de 1996, llegando a aprobar la Cámara de Diputados el 31 de julio de 1996 una serie de reformas y adiciones constitucionales. La reforma al artículo 122 establece que los habitantes del Distrito Federal elegirán directamente al Regente en 1997 y en el año 2000 a los delegados correspondientes ${ }^{2}$.

En él marco de la reforma política negociada por el Jefe del Distrito Federal, la Asamblea de Representantes y los partidos políticos, en 1993 se presenta un dictamen ante la Cámara de Diputados para la creación de los Consejos de Ciudadanos del Distrito Federal.

Los Consejos de Ciudadanos constituyen una nueva figura en la legislación del Distrito Federal, que establece la elección de $\mathbf{3 6 5}$ consejeros ciudadanos en otras tantas áreas vecinales en que se ha dividido la entidad. Estos se agrupan en $\mathbf{1 6}$ consejos de ciudadanos correspondientes a cada delegación en que políticamente se constituye el Distrito Federal. Durante el mes de junio de 1995 se discutió la Ley de Participación Ciudadana para el Distrito Federal, y el Partido Revolucionario Institucional aprobó, en ausencia de los demás partidos (PAN, PRD, PT y PVEM), el artículo 71 que señala que "no podrán utilizarse emblemas, frases, leyendas y colores de partido político alguna". En esta dirección el artículo 60 establece que "Los Consejos de Ciudadanos serán electos por fórmula [...]" (Ley de Participación Ciudadana del Distrito Federal, 1995).

La primera elección de esta instancia de participación fue el 12 de noviembre de $\mathbf{1 9 9 5}$, pero hubo un gran abstencionismo, pues sólo votó alrededor de $20 \%$ de los electores. Sea como fuere, la función genérica que deberán desempeñar los Consejos de Ciudadanos es ser "[...] órgano de representación vecinal y de

${ }^{2}$ La Iniciativa de Reformas Constitucionales en Materia Electoral significó cambios y adiciones en los siguientes 17 artículos constitucionales: $35,36,41,54,56,60,73,74,94,98$, 99, 101, 105, 108, 110, 116 y 122. Para el caso del Distrito Federal, la reforma al artículo 122 implica también la transformación de la Asambleade Representantesen Congreso Local, con la única limitación de que no podrá expedir el Estatuto de Gobierno del Distrito Federal, lo cual continuará siendo responsabilidad del Congreso de la Unión. participación ciudadana" (Departamento del Distrito Federal, $\mathbf{1}^{\circ} \mathrm{de}$ agosto de 1994: artículo 120). El Estatuto de Gobierno del Distrito Federal en su artículo 129 les asigna 10 funciones específicas, entre las que destacan: $i$ ) aprobar, supervisar y evaluar los programas operativos delegacionales anuales; $i$ i) presentar y dar seguimiento a las denuncias ante las autoridades competentes; iii) proponer la atención a problemas prioritarios en la prestación de servicios públicos; y, iv) participar en el cumplimiento del programa de la delegación en materia de uso de suelo y del plan parcial de desarrollo.

Los derechos y obligaciones de los ciudadanos y las funciones de los diversos órganos del Distrito Federal están regulados por un conjunto de leyes, reglamentos, programas, decretos y acuerdos que constituyen una superestructura legal de gran complejidad. En lo que sigue se presenta, en forma por demás esquemática, aquéllos de corte urbanístico que regulan la estructura y expansión del tejido urbano del Distrito Federal, con objeto de proporcionar una imagen totalizadora de su normatividad urbanística.

\section{a Leyes urbanas}

\section{i. Ley Orgánica del Departamento del Distrito Federal}

Esta ley establece las normas de gobierno para la entidad. En ella se enlistan las diferentes unidades administrativas mediante las cuales el Jefe del Departamento ejerce sus atribuciones, así como la asignación de las tareas legislativas del Congreso de la Unión y las judiciales a los Tribunales de Justicia del Fuero Común. En materia de desarrollo urbano del Distrito Federal, al Departamento le corresponde fijar las políticas, estrategias, líneas de acción y sistemas técnicos a que deban sujetarse la planeación urbana y la protección al medio ambiente. Adicionalmente, es de su competencia dictar las políticas generales sobre la construcción y conservación de las obras públicas y sobre los programas de regeneración urbana. Finalmente, la Ley Orgánica delega al Departamento del Distrito Federal la responsabilidad de autorizar la expedición de licencias de construcción, ampliación, modificación, conservación y mejoramiento de todo tipo de inmuebles. 


\section{ii. Estatuto de Gobierno del Distrito Federal}

Durante el proceso de reforma política para la Ciudad de México se debatieron dos posiciones opuestas: transformar al Distrito Federal en el estado 32 de la República o mantenerlo como sede de los poderes federales sin alterar radicalmente su régimen político, pero ideando reformas que lo democraticen. Esta última posición prevalece y en 1987 se crea la Asamblea de Representantes del Distrito Federal como Órgano de representación plural de la ciudadanía, con facultades para normar la vida de la ciudad y representar a su población. De 1992 a 1994, por iniciativa del Regente Manuel Camacho Solís, se trabaja en la reforma del gobierno del Distrito Federal para proporcionarle una forma de gobierno propio. Este proceso culmina el $1^{\circ}$ de agosto de 1994, cuando se decreta el Estatuto de Gobierno del Distrito Federal (Departamento del Distrito Federal, $\mathbf{1}^{\circ}$ de agosto de 1994).

El estatuto sustituye parte de la Ley Orgánica, al señalar que "Se derogan todas aquellas disposiciones que contravengan las contenidas en este Estatuto de Gobierno del Distrito Federal", pero mantiene a "la Ley que regule la administración pública del Distrito Federal [...]". El Estatuto está constituido por seis títulos subdivididos en 13 capítulos y 132 artículos con 16 transitorios: título primero, Disposiciones Generales; título segundo, De los Derechos y Obligaciones de Carácter Público; título tercero, De las Atribuciones de los Poderes de la Unión para el Gobierno del Distrito Federal; título cuarto, De las Bases de la Organización y Facultades de los Órganos Locales de Gobierno del Distrito Federal; título quinto, De las Bases para la Organización de la Administración Pública, del Distrito Federal y la Distribución de Atribuciones entre sus Organos; y, título sexto, De los Consejos de Ciudadanos.

Para los propósitos del presente trabajo únicamente interesa destacar sus principales característicascon implicaciones urbanísticas. El artículo 8 señala como Órganos de Gobierno del Distrito Federal: La Asamblea de Representantes, El Jefe del Distrito Federal y el Tribunal Superior de Justicia. En el título cuarto se indica que la Asamblea de Representantes realiza la función legislativa, teniendo facultades según el artículo 42 para formular observaciones al Programa General de Desarrollo del Distrito Federal y legislar en materia de administración pública local, bienes de dominio público y privado, participaciónciudadana, planeación del desarrollourbano, transporte urbano y tránsito, servicio de limpia, fomento económico, protección y empleo, entre otros. En esta dirección, dentro de las obligaciones del Jefe del Distrito Federal se encuentran las de iniciar leyes y decretos, expedir reglamentos, nombrar y remover libremente a titulares de dependencias del Distrito Federal, presentar a la Asamblea la Ley de Ingresos y Egresos, dirigir la planeación y ordenamiento del desarrollourbano, así como formular el Programa General de desarrollo de la Ciudad, entre sus principales. Cabe destacar la sección tercera del capítulo I, titulo cuarto, sobre la Coordinación Metropolitana, pues como se sabe el área urbana real de la Ciudad de México se localiza (45.6\%) en el Distrito Federal y en el Estado de México (54.4\%), por lo que la existencia de algún tipo de instancias de corte metropolitano son cada vez más imprescindibles. El artículo 69 señala que el Distrito Federal participará en la planeación y ejecución de acciones coordinadas con la federación, estados y municipios en materia de asentamientos humanos, protección al ambiente, transporte, agua potable y drenaje, basura y seguridad pública, para lo cual se establecerán comisiones metropolitanas (artículo 70).

Finalmente, el título quinto observa que la administración del Distrito Federal será central, desconcentrada y paraestatal (artículo 87). La parte central está conformada por la Jefatura, las secretarías, las delegaciones y la Procuraduría de Justicia. Las 16 delegaciones en que se subdivide el Distrito Federal, sin embargo, serán órganos administrativos desconcentrados para una más expedita atención de los requerimientos de la población.

El Estatuto de Gobierno del Distrito Federal, en síntesis, hace las veces de la constitución que norma la convivencia de los habitantes de la república, constituyendo un avance significativo del proceso de democratización de la entidad donde se asientan los poderes federales de México.

Además de la Ley Orgánica y del Estatuto, las principales leyes vigentes son: $i$ ) Ley de Desarrollo Urbano del Distrito Federal (Diario Oficial de la Federación del 7 de enero de 1976, modificada el 28 de diciembre de 1987, el 4 de enero de 1991 y el 7 de febrero de 1996); ii) Ley sobre el Régimen en Propiedad en Condominio de Inmuebles para el Distrito Federal (Diario Oficial del 28 de Diciembre de 1972, modificada el 9 de mayo de 1986 y el 23 de junio de 1993); iii) Ley General de Equilibrio Ecológico y Protección al Ambiente (Ley federal con aplicación en el Distrito Federal; Diario Oficial del 28 de enero de 1988); iv) Ley de Seguridad Pública (Diario Oficial del 19 de julio de 1993); y, v) Ley de Notariado para el Distrito Federal (Diario Oficial del 8 de enero 
de 1980, modificada el 13 de enero de 1986). Considerando los objetivos de este trabajo, a continuación se presentan las características de las dos primeras leyes señaladas.

\section{iii. Ley de Desarrollo Urbano del Distrito Federal, 1996}

La versión actual de esta ley es muy reciente, habiendo sido publicada en el Diario Oficial de la Federación el 7 de febrero de 1996. Esta nueva ley sustituye a la antigua Ley de Desarrollo Urbano del 7 de enero de 1976, que había sido únicamente modificada el 28 de diciembre de 1987 y el 4 de enero de 1991. Aun con estas revisiones, la ley de 1976 presenta una serie de inconsistencias derivadas de su inadecuación al nuevo artículo 122 constitucional que establece las bases del sistema de gobierno del Distrito Federal, a la actual Ley General de Asentamientos Humanos del 21 de julio de 1993, así como al Estatuto de Gobierno del Distrito Federal del $1^{\circ}$ de agosto de 1994.

La Ley de Desarrollo Urbano del Distrito Federal de 1996 está constituida por nueve títulos: i) Disposiciones generales; ii) De los órganos en materia de la ley; iiz) De la planeación del desarrollo; iv) Del ordenamiento territorial; v) De la ejecución de los programas; vi) De la participación social y la participación privada; vii) De los estímulos y los servicios; viii) De las licencias, certificaciones y medidas de seguridad; y, ix) De las sanciones y procedimientos.

El título 1, en su primer artículo, establece como objeto de la ley fijar las normas básicas de planeación y de desarrollo de los centros de población, así como determinar las características de los usos del suelo. A continuación establece una serie de propósitos para mejorar la calidad de vida de la población, tales como optimizar el ordenamiento territorial, propiciar el arraigo y distribución armónica de la población, para lo cual señala que en los programas específicos se diseñarán las acciones requeridas para lograrlos. También plantea una serie de metas en materia del arraigo de la población en las delegaciones centrales (Cuauhtémoc, Venustiano Carranza, Miguel Hidalgo y Benito Juárez), y prohibe la urbanización en las sierras de la entidad (Sierra de Guadalupe, de las Cruces, Ajusto y Santa Catarina) y en lechos de antiguos lagos.

El título II establece en su artículo 8 que las autoridades en materia de desarrollo urbano son cuatro: i) la Asamblea de Representantes; i $\mathbf{z}]$ el Jefe del Distrito Federal; iiz] la Secretaría de
Desarrollo Urbano y Vivienda; y iv) los Delegados del Distrito Federal. Los artículos 9, 10, 11 y 12 puntualizan las atribuciones de cada una de estas instancias, señalando que la Secretaría de Desarrollo Urbano y Vivienda es la encargada de realizar los programas de desarrollo urbano y la Asamblea de Representantes de aprobarlos.

Considerando el objetivo básico de esta ley, los títulos III y IV son los más importantes. Mientras que la ley de 1976 señala la existencia de un plan director subdividido en un plan general y los planes parciales, la de 1996 establece un programa general, programas delegacionales y programas parciales. Adicionalmente, se proponen programas anuales para vincular la planeación urbana con la presupuestal, haciendo en principio posible otorgar los requerimientos financieros para alcanzar las metas establecidas. Independientemente de lo irrelevante de cambiar el sustantivo de plan por programa, al menos formalmente es claro que la ley de 1996 otorga un mayor rango a la planeación que su antecesora, al incorporar la figura de programas delegacionales y anuales.

El artículo 18 señala que el programa general deberá contener 10 puntos centrales, incluyéndose el diagnóstico y pronóstico del desarrollo urbano en el capítulo I sobre la fundamentación y motivaciones. En forma un tanto desarticulada agrega el diseño de una imagen objetivo, una estrategia y metas generales, el ordenamiento del territorio, la estructura vial, el sistema de transporte, las acciones estratégicas e instrumentos, acuerdos administrativos de coordinación y, finalmente, cuestiones sobre la información gráfica. Es posible que la minimización de un diagnóstico y pronóstico riguroso del desarrollo urbano del Distrito Federal, así como la ausencia de la dimensión económica y social de la urbe, pongan en riesgo la adecuada implementación de este tipo de ejercicios. En forma simplificada y adecuándolos a su contexto, los programas delegacionales y parciales siguen la anterior estructura de contenido del programa general. El título II de la Ley agrega una serie de consideraciones sobre la aplicación, tramitación, modificación y evaluación de los programas.

El título IV Del Ordenamiento Territorial comprende un conjunto de disposiciones sobre la relación de los usos del suelo con las actividades y derechos de sus habitantes, así como la zonificación del suelo y las normas de ordenación.

En la Ley de Desarrollo Urbano de 1976 el territorio del Distrito Federal se dividía en: $\hat{\imath}$ ) área de desarrollo urbano, y, ii) área 
de equilibrio ecológico. Las primeras estaban comprendidas por zonas urbanizadas, zonas de reserva y zonas de amortiguamiento.

La Ley de Desarrollo Urbano del Distrito Federal de 1996 clasifica en su artículo 30 el territorio de la entidad como: $i$ ) suelo urbano, y, ii) suelo de conservación. A este nivel la nueva ley no presenta ninguna modificación respecto a la anterior, salvo el cambio de nombre de estos dos grandes'rubros de uso de suelo, pero en su artículo 31 presenta el concepto de "áreas de actuación", para las cuales el Programa General deberá determinar los objetivos y políticas específicas. En este artículo se identifican las siguientesáreas de actuación del suelo urbano: $i$ ) áreas con potencial de desarrollo ii) áreas con potencial de mejoramiento; iii) áreas con potencial de reciclamiento; iv) áreas de conservación patrimonial; y, v) áreas de integración metropolitana. Las áreas de actuación del suelo de conservación son: $i$ ) áreas de rescate; $i$ i) áreas de preservación; y, iii) áreas de producción rural y agroindustrial.

La identificación de este tipo de "áreas de actuación", que la ley señala deberán incorporarse en el Programa General, probablemente permitirá orientar más específicamente los esfuerzos de las autoridades para planear y regular el crecimiento y refuncionalizar el suelo en el Distrito Federal. Más adelante, al analizar el Programa General de 1996, se podrá observar a qué nivel se presentará esta tipología del uso general del suelo.

El capítulo uno de este título IV termina señalando la clase de usos de suelo para los dos tipos de territorio (artículo 32), y las normas de intensidad de las construcciones (artículo 33). El capítulo dos presenta en dos artículos la coordinación de acciones para determinar las áreas de reservas territoriales (artículo 34) y las del crecimiento de los poblados rurales (artículo 35). El capítulo tres, por su parte, incluye en los artículos del 36 al 47 las normas relacionadas con la fusión, subdivisión y relotificación de terrenos.

Los títulos V, VI, VII, VIII y IX de la ley establecen las características de la ejecución de los programas; de la participación social y privada; de los estímulos fiscales y financieros, así como de los servicios urbanos; de las licencias y certificaciones; $y$, finalmente, de las sanciones y procedimientos.

La ley de 1996 remite en su articulado que será necesario expedir un reglamento de la ley donde se establecerán los criterios específicos para su operatividad. El artículo transitorio tercero señala que dicho reglamento se deberá realizar en un plazo de 180 días naturales a partir de su entrada en vigor, esto es, que el plazo vence el 8 de agosto de 1996. En la octava sesión ordinaria del Consejo
Asesor de Desarrollo Urbano del Distrito Federal, celebrada el 21 de agosto de 1996, se presentó un Proyecto de Reglamento de La Ley de Desarrollo Urbano fechado el 12 de agosto, cuya propuesta final se presentará a la Asamblea de Representantes en septiembre de 1996. No siendo posible comentar este reglamento por razones de espacio, se puede adelantar que será muy polémico trasladar la obligación de prestar los servicios urbanos a los promotores inmobiliarios de los conjuntos que desarrollen, tal como se plantea en su artículo 57. Cabe señalar que en la nueva ley la figura de conjunto sustituye a la de fraccionamiento. Se puede mencionar, no obstante, que el reglamento se presenta en los tiempos previstos y que es acertado separarlo de la ley para hacer más expedita la permanente adecuación que la dinámica urbana exige de los reglamentos establecidos, sin requerir la modificación misma de la ley.

iv. Ley sobre el Régimen de Propiedad en Condominio de Inmuebles para el Distrito Federal y Territorios Federales'

Esta Ley de Condominios, decretada en 1972 y adicionada en 1986, declara de utilidad pública la constitución del régimen de propiedad en condominio y las acciones de regeneración urbana en el Distrito Federal. Se establece que para constituir un régimen de propiedad en condominio se debe tener una declaración que expida la autoridad competente del DDF con el fin de verificar si el proyecto es viable siguiendo las previsiones legales del desarrollo urbano, de planificación y la prestación de servicios públicos. Una vez erigido este régimen, debe inscribirse en el Registro Público de la Propiedad (artículos 3 y 4).

La ley de Condominios se divide en los siguientes ocho capítulos, y tiene un total de 51 artículos: I. Del régimen de la propiedad en condominio; II. De los bienes de propiedad común; m. De las asambleas y del administrador; IV. Del reglamento del condominio; V. De los gastos, obligaciones fiscales y controversias; VI. De los gravámenes; VII. Destrucción, ruina y reconstrucción del condominio; y, vIII. Del régimen de propiedad en condominio de carácter vecinal. 
Los primeros dos capítulos presentan las características básicas que deben cubrir los condominios, y el resto se refieren a su organización interna. En el artículo 1 se señala que los condominios pueden ser verticales, horizontales o mixtos, y cuáles son los derechos de sus propietarios. Los artículos $\mathbf{2}$ al $\mathbf{1 0}$ del capitulo I señalan cuándo se origina el régimen de propiedad en condominio, una declaratoria pública y otras características generales de dicho régimen. En el capitulo $\Pi$ se describen los elementos que son comunes, cómo hacer uso de ellos y de los derechos de los condóminos ${ }^{4}$.

En el Distrito Federal el régimen de propiedad en condominio se ha utilizado en forma generalizada tanto en el caso de edificios departamentales como en el de casas habitación. Bajo este régimen se tiene la ventaja de utilizar elementos comunes como calles internas, vestíbulos, jardines, vigilancia, pozos y cisternas, etc., cuyos costos se prorratean entre los condóminos. La mayor seguridad que representan es, sin duda, una de las razones que explican su gran utilización.

La ley de Desarrollo Urbano y la Ley de Condominios del Distrito Federal, junto con la Ley General de Asentamientos Humanos y las disposiciones constitucionales en materia de la propiedad y de las atribuciones de las autoridades, constituyen el marco jurídico sobre el cual se establece un conjunto de programas, reglamentos, decretos, normas y acuerdos expedidos por las diferentes dependencias del DDF que rigen las características de su expansión y estructuración territorial.

\section{B. Reglamentación urbanistica}

Las leyes se complementan con reglamentos, que en forma metódica señalan los procedimientos para hacer posible la correcta aplicación de las primeras. En materia urbana los reglamentos suelen ser la guía práctica que regula el uso del suelo y las actividades constructivas de la ciudad, siendo los documentos más significativos para el ordenamiento urbano. Los principales reglamentos existentes en el Distrito Federal se enlistan a continuación, señalándose la fecha de su última publicación en el Diario Oficial (DO):

i. Reglamento de Construcciones del Distrito Federal (DO, 2 de agosto de 1993).

ii. Reglamento de Zonificación del Distrito Federal (DO, 3 de julio de 1987).

iii. Reglamento de la Zona de Urbanización de los Ejidos (DO, 25 de mayo de 1954).

iv. Reglamento de la Ley General de Equilibrio,Ecológico y Protección del Ambiente en materia de impacto ambiental (DO, 7 de junio de 1988).

v. Reglamento de la Ley General de Equilibrio Ecológico y Protección del Ambiente en materia de residuos peligrosos (DO, 25 de noviembre de 1988).

vi. Reglamento de la Ley General de Equilibrio Ecológico y Protección del Ambiente en materia previsión y control de la contaminación generada por vehículos automotores que circulan por el Distrito Federal y los municipios de la zona conurbada (DO, 25 de noviembre de 1988).

vii. Reglamento de la Ley General de Equilibrio Ecológico y Protección del Ambiente en materia de previsión y control de la contaminación de la atmósfera (DO, 25 de noviembre de 1988).

viii. Reglamento para el servicio de limpia del Distrito Federal (DO, 27 de julio de 1989).

ix. Reglamento del servicio de agua y drenaje del Distrito Federal (DO, 6 de agosto de 1993).

x. Reglamento de Estacionamientos Públicos (DO, 27 de mayo de 1991).

xi. Reglamento para el uso y preservación del Bosque de Chapultepec (DO, 14 de agosto de 1986).

xii. Reglamento para el uso y preservación del Bosque de San Juan de Aragón (DO, 29 de abril de 1987).

xiii. Reglamento para el uso y preservación del Parque de las Aguilas (DO, 11 de junio de 1987).

xiv. Reglamento para el uso y preservación del Parque Cultural y Recreativo Desierto de los Leones (DO, 18 de agosto de 1988).

xv. Reglamento para la atención de los minúsvalidos en el Distrito Federal (DO, 16 de febrero de 1990).

xvi. Reglamento para la protección de los no fumadores del Distrito Federal (DO, 2 de agosto de 1993).

xvii. Reglamento de anuncios para el Distrito Federal (DO, 20 de abril de 1982). 
xviii. Reglamento de Cementerios del Distrito Federal (DO, 28 de diciembre de 1989).

Por limitaciones de espacio, a continuación se hace un breve resumen del reglamento de construcciones y del de zonificación, que son las disposiciones fundamentales que determinan la producción del espacio construido en el Distrito Federal.

\section{i Reglamento de Construcciones del Distrito Federal (RCDF)}

Este reglamento, actualmente vigente, se publicó en la Gaceta del Departamento del Distrito Federal el 6 de junio de 1987 y abroga al reglamento correspondiente expedido en 1976. El nuevo reglamento presenta disposiciones más rigurosas en materia de diseño estructural para reforzar la estabilidad de las construcciones en el Distrito Federal, cuya necesidad se deriva de los graves daños ocasionados por los sismos de septiembre de $\mathbf{1 9 8 5}$ y de la necesidad de reducir el nivel de riesgo futuro para los habitantes.

El RCDF es el instrumento más importante que rige la estructuración del espacio urbano, pues es el conjunto de normas técnicas a las que se deben sujetar la localización y características de las construcciones en la entidad. Está constituido por $\mathbf{1 3}$ títulos subdivididosen capítulos que en conjunto comprenden $\mathbf{3 5 3}$ artículos más trece transitorios, en los cuales se integran las normas técnicas necesarias para garantizar un diseño estructural que refuerce la estabilidad de las construcciones e instalaciones, adecuar la ciudad para la vida de los parapléjicos, mejorar la imagen urbana, así como promover el mantenimiento adecuado de las construcciones de los servicios públicos.

Ante la imposibilidad de analizar en detalle este reglamento fundamental de ordenación urbana del Distrito Federal, se señalan tres de sus aspectos cardinales.

El título segundo del RCDF, titulado "Vías públicas y otros bienes de uso común", esta constituido por seis capítulos. En el 1, de Generalidades, se define como vía pública a "[...] todo espacio de uso común que por disposición del Departamento se encuentre destinado al libre tránsito, de conformidad con las leyes y reglamentos en la materia, así como todo inmueble que de hecho se utilice para ese fin" (Gaceta Oficial del Departamento del Distrito Federal, 6 de junio de 1987:10). El capitulo II en su artículo 10 crea un "Comité de Coordinación y Normas de Infraestructura Urbana" con el fin de coordinar a la entidades públicas y privadas que intervienen en la realización de la infraestructura, mientras que en los artículos $\mathbf{1 1}$ al 18 se norman las acciones privadas dentro de la vía pública. Cabría destacar el capitulo $\mathrm{V}$, sobre alineamiento y uso del suelo, permiso cuyo otorgamiento constituye un requisito básico para la obtención de una licencia de construcción, que es indispensable para que los particulares realicen las edificaciones que en conjunto definen la calidad urbanística de la ciudad. Si se reúnen los requisitosexistentes, el Departamento del Distrito Federal expedirá la constancia sobre uso de suelo, alineamiento y/o número oficial. En la práctica no existen dificultades para obtener esta constancia si los predios se localizan dentro del área urbana del Programa General de Desarrollo Urbano del Distrito Federal y de los Planes Parciales Delegacionales. Sin embargo, el crecimiento observado en la "zona de amortiguamiento", en las Áreas de Conservación Ecológica, así como en las localidades rurales del Distrito Federal, ocurre en forma irregular pues no se les concede la constancia de alineamiento y número oficial y, por ende, el permiso de construcción. Esto origina una expansión irregular de la mancha urbana y una significativa diferencia entre la ciudad real y la virtual.

El título cuarto es el de Licencias y Autorización, aspecto crucial de la planeación urbana y de vital interés para los propietarios de predios por ser la autorización oficial para construir edificaciones. El artículo $\mathbf{5 3}$ señala el tipo de construcciones que deberán obtener la licencia en las oficinas centrales del Departamento del Distrito Federal y no en las delegaciones: conjuntos habitacionales, oficinas y tiendas de autoservicio de más de 10 mil metros cuadrados, hospitales, edificaciones de educación superior, industria pesada y mediana, etc. El artículo $\mathbf{5 6}$ establece los requerimientos de las solicitudes de licencia de construcciones, que cuando se trate de obra nueva son: $i$ ) constancia de uso de suelo, alineamiento y número oficial vigente; ii) dos copias del proyecto arquitectónico detallado; iiz) dos copias del proyecto estructural de la obra; y, iv) licencia de uso del suelo, en su caso. Una vez aprobados estos requisitos, para la obtención de la licencia se tendrán que pagar los derechos correspondientes. Cabe destacar que las dimensiones mínimas de los predios para otorgar licencia de construcción serán de $\mathbf{9 0}$ metros cuadrados de superficie y seis de frente a la vía pública (artículo 58). La construcción irregular de viviendas que no cumplen con estas especificaciones es un fenómeno reconocido por las autoridades del Distrito Federal, aunque no se tiene cuantificación precisa sobre su magnitud. 
Finalmente, cabría señalar que el título quinto, sobre el Proyecto Arquitectónico, y el título sexto, titulado Seguridad Estructural de las Construcciones, constituyen la parte esencial del RCDF. El título quinto consta de 6 capítulos donde se detallan los aspectos técnicos de los elementos arquitectónicos de las construcciones, la superficie construida máxima (artículo 76), las áreas sin construir, el número de cajones de estacionamiento según tipología de construcciones (artículo 80), dimensiones y características según clase de edificación (artículo 81), los requisitos de higiene y servicios (dotación de agua, número de excusados y lavabos), nivel de iluminación, tipo y tamaño de las puertas, dimensiones de corredores y escaleras, dispositivos de seguridad, y otros. El título sexto complementa al anterior, presentando pormenorizadamente las características que deben tener las construcciones con objeto de alcanzar un nivel de seguridad adecuado para evitar fallas estructurales. Especifica los parámetros técnicos que deben cubrirse en el diseño de toda estructura en relación a las cargas muertas, cargas vivas y los efectos de sismos y vientos (artículos 172 al 240).

El RCDF presenta en su título séptimo las condiciones en que se desarrolla el procedimiento de construcción; el uso, operación y mantenimiento de los inmuebles, en su título octavo; las ampliaciones de obra (título noveno), demoliciones (título décimo), y explotación de material pétreo (título décimo primero). Finalmente, en el título décimo segundo se incluyen las medidas de seguridad y en el décimo tercero la inspección, sanciones y recursos de inconformidad.

El RCDF constituye un documento técnico exhaustivo y bien elaborado, por lo que la problemática que representa la irregularidad de algunas construcciones tendrá que enfrentarse en el ámbito del aparato administrativo que lo implementa y las condiciones económicas, sociales y políticas en que se inscribe la ciudad. En general, se estima que 23\% del área total urbanizada de la Ciudad de México presenta condiciones de ilegalidad en su tenencia y, por ende, en sus construcciones. Esta superficie equivale a 1.2 millones de lotes irregulares en los que viven 6.7 millones de personas que carecen de los servicios e infraestructura urbana mínimos(Legorreta, 1992:205). La solución de esta problemática no depende de la existencia de reglamentos adecuados, sino de los cambios requeridos en la estructura socioeconómica prevaleciente. La transformación de esta última debería de constituir, por énde, uno de los objetivos básicos de los planes de desarrollo urbano.

\section{ii. Reglamento de Zonificación para el Distrito Federal (RZDF)}

Este Reglamento establece las normas en materia de zonificación y asignación de los usos, destinos y reservas territoriales. El documento consta de seis capítulos subdivididosen 62 artículos. Para la ordenación y regulación de la superficie del Distrito Federal, este reglamento la clasifica como zonificación primaria y zonificación secundaria de una forma un tanto ambigua. La zonificación primaria esta comprendida por los siguientes usos del suelo, que se determinan en el Programa Director:

- área de desarrollo urbano

- zonas urbanizadas

- zonas de reservas territoriales

- zonas de amortiguamiento

- área de conservación ecológica

La zonificación secundaria asigna. a las zonas anteriores los usos y destinos de suelo según se determine en los Programas Parciales.

El capitulo II del RZDF señala que el Jefe del Distrito Federal deberá hacer las declaratorias de destinos de suelo para fines públicos y los usos para los fines privados. El capitulo m, De los Planos de Zonificación, señala que los planos relativos a la zonificación primaria deberán ser a escala 1:50,000; los de zonificación secundaria de 1:10,000; y los de las declaratorias de 1:2,000.

El capitulo IV en su artículo 29 clasifica los usos y destinos en los siguientes rubros: $i$ ) Habitacional; $i$ ) Servicios; $i$ ii) Industrial; iv) Áreas verdes y espacios abiertos; v) Infraestructura; y, vi) Agrícola, pecuario y forestal. En lo que podría considerarse la parte central de este reglamento, los artículos 30 y 35 subdividen cada uno de los seis usos de suelo anteriores en sus diversos componentes.

El capitulo v señala que la licencia de uso de suelo será requerida obligatoriamente para el otorgamiento de la licencia de construcción, y el VI agrega lo referente a las inspecciones de verificación de usos de suelo establecidas, las multas por violaciones y la posibilidad de interponer un recurso de inconformidad por los ciudadanos que se consideren afectados.

En síntesis, el RZDF define en forma genérica las reglas en materia de asignación de usos y destinos del suelo, los cuales deben establecerse específicamente -en un conjunto de planos correspondientes. Esta característica hace que este reglamento sea 
verdaderamente secundario, y sus preceptos esenciales fácilmente se podrían incorporar al RCDF.

\section{c. Acuerdos en materia urbana}

Los acuerdos públicos son resoluciones adoptadas por las diferentes instancias de gobierno con el fin de instrumentar medidas ad hoc relacionadas con la leyes, planes, programas, reglamentos y, en general, todo los relacionado con la administración gubernamental. En relación con las leyes y reglamentos anteriormente presentados, se puede mencionar la existencia de los siguientes acuerdos:

1. Acuerdo por el que se declara prioritaria la regularización de la tenencia de la tierra en el Distrito Federal y la creación de reservas territoriales (DO, 27 de julio de 1983).

11. Acuerdo por el que se crea la Comisión de Límites del Distrito Federal, que tendrá como objeto auxiliar a las autoridades del Departamento del Distrito Federal en la salvaguarda del territorio propio del Distrito Federal (DO, 23 de mayo de 1984; modificaciones, 22 de noviembre de 1985).

iii. Acuerdo por el que se aprueba la nueva versión del Programa General del Programa Director de Desarrollo Urbano para el Distrito Federal (DO, 16 de julio de 1987).

iv. Acuerdo por el que se aprueba la versión 1987 de los Programas Parciales de Desarrollo Urbano de las 16 Delegaciones del Distrito Federal (DO, 16 de julio de 1987; modificaciones, 14 de junio de 1988 y 23 de marzo de 1993; esta última respecto a la Delegación Alvaro Obregón).

v. Acuerdo por el que se aprueba la versión $1987 \mathrm{de}$, los Programas Parciales de los Poblados Localizados en el Area de Conservación Ecológica de las Delegaciones del Distrito Federal (DO, 16 de julio de 1987; modificaciones, 5 de junio de 1988).

vi. Acuerdo por el que se establece que los conjuntos habitacionales construidos por el Fideicomiso de Vivienda, Desarrollo Social y Urbano del Distrito Federal, así como las acciones de regeneración urbana y sustitución de vecindades, se sujetarán a las disposiciones contenidas en el mismo (DO, 23 de marzo de 1988).

vii. Acuerdo que contiene las disposičiones a las que se sujetarán los conjuntos habitacionales construidos y en proceso de construcción por el Fideicomiso de Vivienda, Desarrollo Social y Urbano del Departamento del Distrito Federal (DO, 29 de julio de 1988).

viii. Acuerdo referente a los Programas de Regulación Territorial que se lleven a cabo por el Distrito Federal o sus entidades sectoriales (DO, 5 de abril de 1989).

ix. Acuerdo por el que se crean la Oficinas Centrales de Gestión para Licencias de Construcción y Documentos del Distrito Federal en el Colegio de Arquitectos de México A. C. y en el Colegio de Ingenieros Civiles de México A. C. (DO, 21 de septiembre de 1989).

X. Acuerdo por el que se delega, a los titulares de las Delegaciones del Distrito Federal, la facultad de otorgar y expedir las licencias de usos de suelo en el área urbana dentro de sus respectivas jurisdicciones (DO, 21 de septiembre de 1989).

xi. Acuerdo por el que se crea el Consejo para el Mejoramiento de la Imagen Urbana del Distrito Federal, órgano de consulta y asesoramiento del Jefe del Departamento del Distrito Federal en asuntos relacionados con la definición de políticas de elaboración, ejecución y evaluación de programas concernientes al mejoramiento estético de la ciudad (DO, 28 de febrero de 1990).

xii. Acuerdo por el que se crea el Consejo Asesor para la Ejecución del Programa de Rescate Ecológico de Xochimilco (DO, 28 de febrero de 1990).

xiii. Acuerdo por el que se determina que los usos de suelo que se encuentran permitidos en las Zonas Especiales de Desarrollo Controlado y que no cuenten con un Programa de Mejoramiento, no se les aplique la denominación de condicionados en el Distrito Federal (DO, 10 de enero de 1991).

xiv. Acuerdo por el que con objeto de apoyar la vivienda de interés social se eximirá, tomando en cuenta el tipo de construcción de que se trate, de parte o de la totalidad de los estacionamientos en el Distrito Federal (DO, 8 de abril de 1991).

xv. Acuerdo que complementa la tabla de usos de suelo para la intensidad de construcciones de oficinas de gobierno y privadas en el Distrito Federal (DO, 29 de julio de 1991; modificaciones, 24 de diciembre de 1991). 

nóviembre de 1992).

Por limitación de espacio, nuevamente, sólo es posible desçribir brevemente algunos de los anteriores acuerdos, pero su título sintetiza su objetivo básico y el lector interesado puede acudir a su consulta directa localizándolos en el Diario Oficial de la Federación según fecha indicada.

i. Acuerdo referente a los programas de regularización territorial que se llevan a cabo por el Departamento del Distrito Federal o sus entidades sectoriales (DO, 5 de abril de 1989)

El Departamento del Distrito Federal, por medio de la Dirección General de Regularización Territorial, acuerda la creación de un programa con la finalidad de regularizar jurídicamente los predios que se encuentran al margen de la ley, otorgando la escritura pública correspondiente. Este programa cuenta con la participación del Colegio de Notarios del Distrito Federal, que de esta manera contribuye a la solución de la problemática habitacional de uno de los sectores más desprotegidos de la sociedad.

El acuerdo será aplicado a los beneficiarios de los programas de regularización territorial que ejecute el Departamento del Distrito Federal o sus entidades sectoriales, siendo que las personas que realicen actos de translación de dominio sin la intervención de las instancias mencionadas, no podrían beneficiarse con este instrumento.

El acuerdo exime del tramite de uso de suelo, constancia de zonificación, licencia de construcción, etc., a los predios que se incorporen a dichos programas, es decir, que ya se consideren regularizados. Adicionalmente, cuando exista la necesidad de construir el régimen de propiedad en condominio, se exenta 'de cumplir con los permisos, autorizaciones y demás trámites y requisitosque se señalan en el artículo 3 de la Ley de dicho régimen, y sólo se autorizan las fusiones, divisiones o relotificaciones de predios que sean estrictamente necesarias.

Finalmente, el Departamento del Distrito Federal delega al titular de la Dirección General de Regularización Territorial y a sus directores de área la facultad de firmar las escrituras que se otorguen.

ii. Acuerdo por el que se crean las Oficinas Centrales de Gestión para licencias de construcción y documentos que se indiquen (DO, 21 de septiembre de 1989)

Considerando que el Área Metropolitana de la Ciudad de México es una de las urbes más pobladas del planeta, se han buscado mecanismos alternativos para atender al gran número de solicitudes recibidas, estudiadas y expedidas, tales como la constancia de uso de suelo, alineamiento y número oficial, la licencia de uso de suelo y de construcción en sus modalidades de obra nueva, ampliación, demolición, cambio de régimen, cambio de uso de suelo y registro de obra.

Este acuerdo crea dos grandes oficinas especializadas encargadas de tramitar dichas solicitudes, como una nueva alternativa para la ciudadanía, mediante el esfuerzo conjunto de las autoridades del Departamento del Distrito Federal y de los Colegios de Ingenieros Civiles A.C. y de Arquitectos de México A.C.

Estas dos oficinas centrales tienen su sede en el Colegio de Arquitectos de México A.C. y en el Colegio de Ingenieros Civiles A.C., estando facultadas para llevar a cabo los trámites antes señalados. No obstante, las Delegaciones continuarán ejerciendo estas atribuciones, además de que supervisarán los trámites que se realicen en las dos oficinas centrales y cuidarán que se corrija cualquier irregularidad, siendo a su vez coordinadas por la Secretaría de Desarrollo Urbano y Vivienda.

iii. Acuerdo por el que se delega en los titulares de las Delegaciones Políticas del Distrito Federal, la facultad para otorgar y expedir las licencias de uso de suelo en el área urbana que sean solicitadas dentro de sus respectivas jurisdicciones(DO, 21 de septiembre de 1989)

Teniendo en cuenta que la zonificación secundaria indica los usos que por su magnitud, complejidad y relación con la estructura urbana no representan mayor alteración a su entorno urbanístico, así como que el Departamento del Distrito Federal se encuentra instrumentando un programa de simplificación administrativa con el objeto de reducir los trámites para la obtención de la licencia de uso de suelo, por este acuerdo se confiere a los titulares de las Delegaciones del Distrito Federal la facultad para otorgar y expedir 
Cuadro 4

Usos y magnitudes máximas de obras en las cuales las delegaciones tienen la facultad de expedir licencias de uso del suelo

\begin{tabular}{|c|c|}
\hline Habitación & $\begin{array}{l}\text { Vivienda unifamiliar y bifamiliar } \\
\text { De } 3 \text { a } 20 \text { viviendas induyendo incremento a la densidad otorgado por } 12 \text { DGRUPE }\end{array}$ \\
\hline Adninistración páblica & $\begin{array}{l}\text { Oficinas dé gobiemo hasta } 100 \mathrm{~m}^{2} \\
\text { Sucursales de banco y casas de cambio hasta } 100 \mathrm{~m}^{2}\end{array}$ \\
\hline $\begin{array}{l}\text { Adminietración privada } \\
\text { Almacenamiento y abastos }\end{array}$ & $\begin{array}{l}\text { Oficinas privadas y consullorios hasta } 100 \mathrm{~m}^{2} \\
\text { Bodegas de acopio y transferencia de productos perecedenos } \\
\text { Bodegas de semillas, huevos, lacteos o abarrotes }\end{array}$ \\
\hline $\begin{array}{l}\text { Thendas de productos } \\
\text { bésacicos y de especialidades }\end{array}$ & $\begin{array}{l}\text { Venta de abarrotes, comestibles, comida elaborada sin comedor o pamaderias hasta } 500 \mathrm{~m}^{2} \\
\text { Venta de granos, senallas, formies, chiles o moles o moltho de nixtamal } \\
\text { Venta de articulos en general hasta } 500 \mathrm{~m}^{2} \\
\text { Farmaclas, boticas o droguerias hasti } 500 \mathrm{~m}^{2}\end{array}$ \\
\hline $\begin{array}{l}\text { Venta de maneriales de } \\
\text { construccion }\end{array}$ & 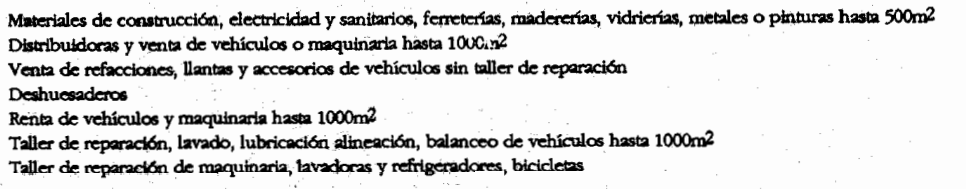 \\
\hline Tiendas de servicto & $\begin{array}{l}\text { Sanitarios públicos, gtmnasios, sauna y masajes (acondictonamiento fisico) } \\
\text { Salas de belleza, peluquerias, lavanderias, tintonertios, sastrerias, laboratorio fotográfico hasta } 500 \mathrm{~m} 2\end{array}$ \\
\hline
\end{tabular}

\begin{tabular}{|c|c|}
\hline Centros de salud & Laboratorios denviles, análisis dínicos, radiografias \\
\hline Asistencia animal & Salones de corte, dínica, dtspensarlos veterinarios y tiendas de animales hasta $500 \mathrm{~m}^{2}$ \\
\hline Educación elemental & $\begin{array}{l}\text { Guanderias, jardines de niños y escuelas para niños atipleos } \\
\text { Escuelas primarias } \\
\text { Academias de danza, belleza, contabilidad, computación hasta } 500 \mathrm{~m} 2\end{array}$ \\
\hline Alimentos y bebidas & $\begin{array}{l}\text { Cafes o fondas (resmumentes sin venta de bebidas alcohalicas) } \\
\text { Vinatichas (vente de bebidas alcoholicas en botella cerrada) }\end{array}$ \\
\hline Recreación soctal & Centros comunitarios, centros culturales y salones para fiestas infentiles hasta $500 \mathrm{~m} 2$ \\
\hline Deportes y recreacion & Canchas deportivas cublertas \\
\hline Servicios funerarios & Agencias funerartas de inhumaciones hasta $500 \mathrm{~m}^{2}$ \\
\hline Transportes terrestres & $\begin{array}{l}\text { Estacionarmientos públicos, hasta } 50 \text { cajones y sitios de taxis } \\
\text { Encterroe o montenimiento de vehículos }\end{array}$ \\
\hline Comunicaciones & Agencias de correo, telégrafos y telefonos \\
\hline Industria ligera & Altmenticka, textll, del calrado, manufacturera y ensemble hasta $1000 \mathrm{~m}^{2}$ \\
\hline
\end{tabular}

Fuente: Dirrio Offial th La Federación, 21 de teptiembre de 1989, Mtrico. 
licencias de uso de suelo en sus respectivas áreas urbanas, siguiendo las magnitudes y usos que se muestran en el cuadro 4

De todas las constancias que los delegados expidan deberán mandar una copia a la Secretaría de Desarrollo Urbano y Vivienda, incluyendo el proyecto aprobado, los planos y los dictámenes de apoyo. Los permisos de usos de suelo de los proyectos de mayor magnitud que los presentados en el cuadro 4 seguirán otorgándose en dicha secretaría.

\section{d. Programas generales, parciales y sectoriales}

Los orígenes de la planeación contemporánea de la capital del país se remontan a 1933, cuando se presenta una primera versión del Plan Regulador del Distrito Federal, así como la Ley de Planificación y Zonificación del Distrito Federal y del Territorio de Baja California. Los trabajos de formulación de este primer plan regulador se prosiguen hasta 1940, año en que se concluye sa versión definitiva (Hiernaux, 1989:214). Entre 1940 y 1970 predomina el empirismo en materia de desarrollo urbana en la Ciudad de México, periodo en que destaca el regente Ernesto Uruchurtu, que la gobernó de 1952 a 1966 mediante un estricto esquema urbanístico sin un plan oficial (Hiernaux, 1989:243).

Es hasta los años setenta cuando se puede hablar del inicio de una planeación urbana institucionalizada a partir de la reforma a la Ley de Planificación del Distrito Federal en 1971 y, más particularmente, al decretarse la Ley de Desarrollo Urbano del Distrito Federal en 1976. A continuación se enlistan los programas generales realizados a partir de ese año, así como los programas parciales y sectoriales vigentes hasta septiembre de 1996, que en conjunto constituyen el instrumento rector de la planeación urbana del Distrito Federal:

\section{i Programas generales}

i.1 Programa General de Desarrollo Urbano del Distrito Federal (DO, 30 de*noviembrede 1976; modificaciones, 18 de marzo de 1980, 17 de mayo de 1982, 16 de julio de 1987 y 30 de abril de 1996).

i.2 Programa de Ordenación de la Zona Conurbada del Centro del País (DO, 2 de diciembre de 1982). i.3 Programa de Desarrollo de la Zona Metropolitana de la Ciudad de México y de la Región Centro (Octubre, 1983)

i.4 Programa Integral contra la Contaminación Atmosférica (Ciudad de México, octubre de 1990).

\section{ii. Programas parciales}

ii.1 Programa Parcial de Desarrollo Urbano de la Delegación Alvaro Obregón.

ii.2 Programa Parcial de Desarrollo Urbano de la Delegación Azcapotzalco.

ii.3 Programa Parcial de Desarrollo Urbano de la Delegación Benito Juárez.

ii.4 Programa Parcial de Desarrollo Urbano de la Delegación Coyoacán.

ii.5 Programa Parcial de Desarrollo Urbano de la Delegación Cuajimalpa.

ii.6 Programa Parcial de Desarrollo Urbano de la Delegación Cuauhtémoc.

ii.7 Programa Parcial de Desarrollo Urbano de la Delegación Gustavo A. Madero.

ii.8 Programa Parcial de Desarrollo Urbano de la Delegación Iztacalco.

ii.9 Programa Parcial de Desarrollo Urbano de la Delegación Iztapalapa.

ii.10 Programa Parcial de Desarrollo Urbano de la Delegación Magdalena Contreras.

ii.11 Programa Parcial de Desarrollo Urbano de la Delegación Miguel Hidalgo.

ii.12 Programa Parcial de Desarrollo Urbano de la Delegación Milpa Alta.

ii.13 Programa Parcial de Desarrollo Urbano de la Delegación Tláhuac.

ii.14 Programa Parcial de Desarrollo Urbano de la Delegación Thalpan.

ii.15 Programa Parcial de Desarrollo Urbano de la Delegación Venustiano Carranza. 
ii.16 Programa Parcial de Desarrollo Urbano de la Delegación Xochimilco.

\section{iii. Programas sectoriales}

iii.1 Programa de Reserva Territorial.

iii.2 Programa de Infraestructura.

iii.3 Programa de Vialidad y Transporte.

iii.4 Programa de Vivienda.

iii.5 Programa de Equipamiento Urbano.

iii.6 Programa de Medio Ambiente.

iii.7 Programa de Desechos Sólidos.

iii.8 Programa de Áreas Verdes.

iii.9 Programa de Salvaguarda de Sitios Patrimoniales.

iii.10 Programa de Prevención y Mitigación de Daños en Casos de Desastre.

iii.11 Programa para el Cinturón Verde de la Ciudad de México. iii.12 Programa de Poblados en el Área de Preservación Ecológica.

iii.13 Programa de Reordenación de Barrios.

iii.14 Programa de Reordenación Industrial.

iii.15 Programa de Mejoramiento del Centro Histórico.

Las limitaciones de extensión del trabajo sólo permiten esquematizar el programa general 1987 y presentar algunos ejemplos de los parciales y sectoriales de ese año, así como incluir el vigente que aprobó la Asamblea de Representantes el 30 de abril de 1996.

\section{i Programa General de Desarrollo Urbano del Distrito Federal, 1987. 1988 (PGDUDF, 87-88) (México, D.F.1987)}

Este programa está estructurado en siete capítulos: I. Antecedentes; II. Situación actual; m. Normatividad; IV. Estrategia; V. Programas Sectoriales; VI. Lineamientos; y, VII. Instrumentos.

En un preámbulo presenta seis tesis básicas que lo orientan:

- Controlar y ordenar el crecimiento de la Zona Metropolitana de la Ciudad de México.

- Contener el crecimiento siguiendo las políticas de desconcentración de industrias contaminantes y la prohibición de nuevos fraccionamientos.
- Reconstruir la Zona Central de la Ciudad de México, que comprende a las delegaciones Gustavo A. Madero, Benito Juárez, Venustiano Carranza y Cuauhtémoc. Para esto se realizará una nueva zonificación según el riesgo sísmico de estas entidades procurando la reducción de la densidad de población y la intensidad de las construcciones.

- La reordenación urbana se basará en 8 sectores que contendrán a los Centros, Subcentros, Corredores Urbanos y Zonas Especiales de Desarrollo Controlado, además del Centro Histórico.

- Conservar el medio ambiente evitando la urbanización del Área de Conservación Ecológica e incrementando la calidad del medio ambiente en el área de desarrollo urbano.

- Desarrollar los instrumentos de planeación y actualizar las normas jurídicas en vigor.

Como parte fundamental de la estrategia, en el capítulo IV se establecen dos áreas básicas en que se divide al Distrito Federal: área de desarrollo urbano y área de conservación ecológica.

Para llevar a cabo la reordenación del Distrito Federal, este programa general divide al área de desarrollo urbano en sectores que contienen a los centros, subcentros, corredores urbanos, centro histórico y zonas especiales de desarrollo controlado, con las siguientes características:

- Sectores urbanos. Sin violentar las jurisdicciones delegacionales, éstos serán un instrumento para la reorganización y refuncionalización de las actividades sociales, admínistrativas y privadas. Los sectores propuestos son Azcapotzalco, Tacuba, Tacubaya, Culhuacán, Iztapalapa, Pantitlán y Tepeyac.

- Centros urbanos. Se pensó consolidar en la ciudad los siguientes puntos estratégicos donde la población de su zona de influencia (1 500,000 habitantes) pueda satisfacer sus diversas necesidades: Azcapotzalco, Tacuba, Tacubaya, Culhuacán, Iztapalapa, Pantitlán y T'epeyac.

- Subcentros urbanos. Estos son áreas complementarias a los centros urbanos, que ofrecerán servicios de menor especialización pero más frecuentemente requeridos por su población de alrededor de 120,000 habitantes, que cubren una superficie promedio de 2 hectáreas. Se planeó realizar acciones de mejoramiento en algunos ya existentes: Coyoacán, Perisur, Tizapan, Chabacano, Bosques de las Lomas, Jamaica, Aeropuerto y Xochimilco. Adicionalmente, se establece promover a los de: Santa Fe, El 

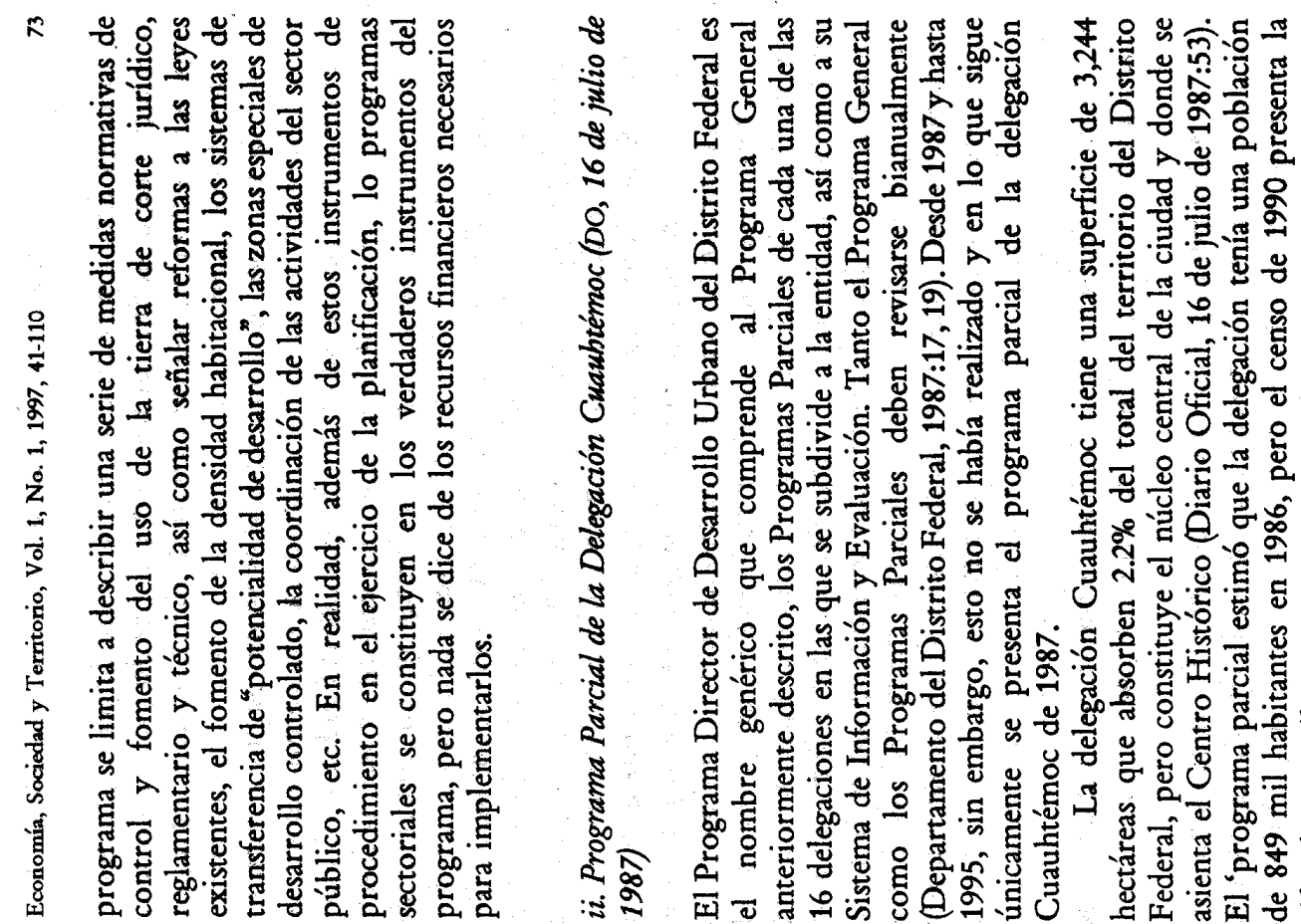

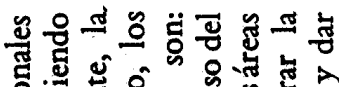

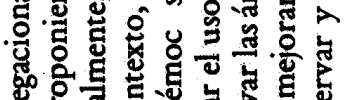

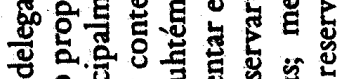

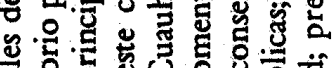

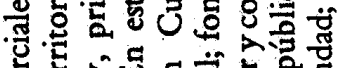

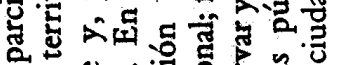

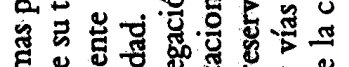
현.

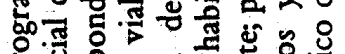

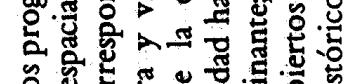

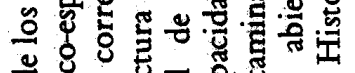

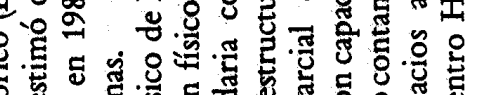

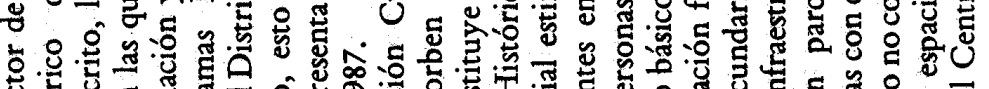

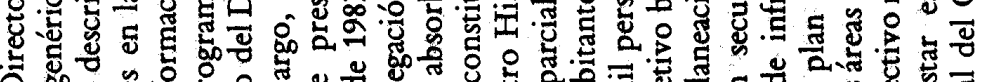

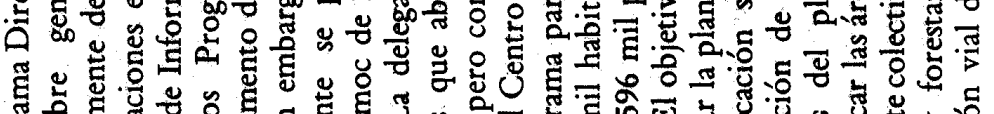

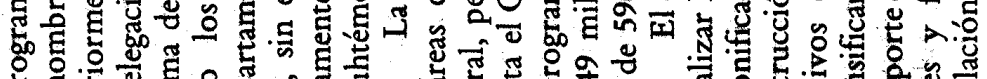

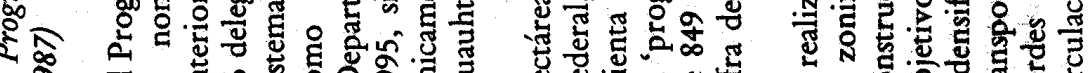
:

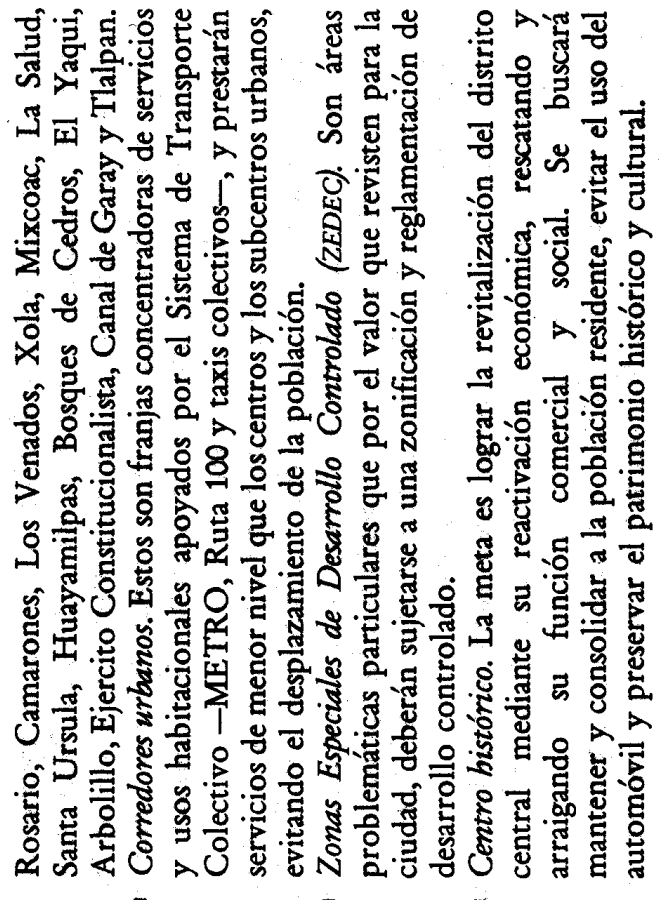

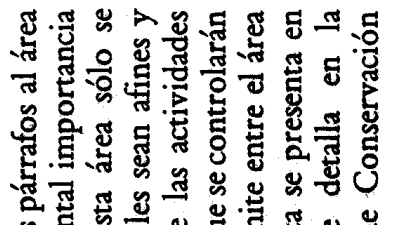

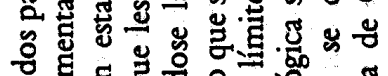

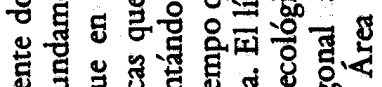

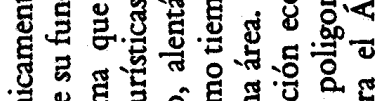

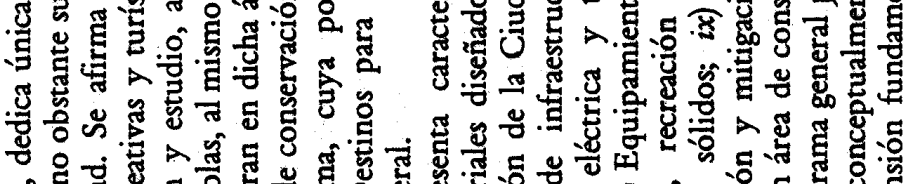

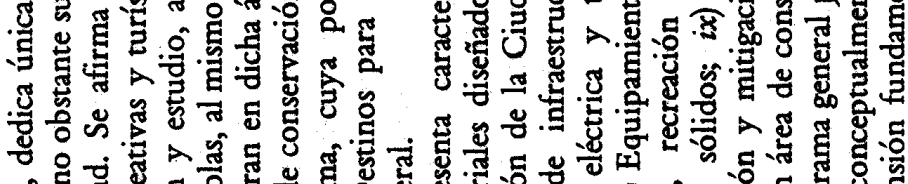

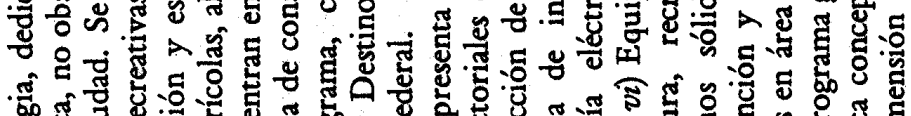

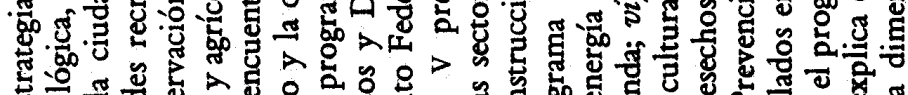

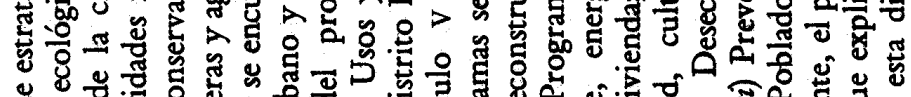

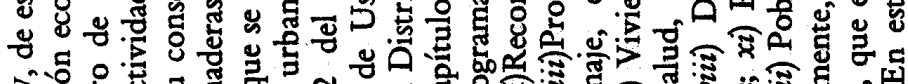
诺 일

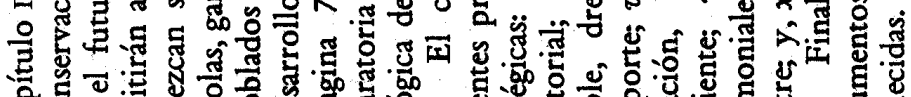

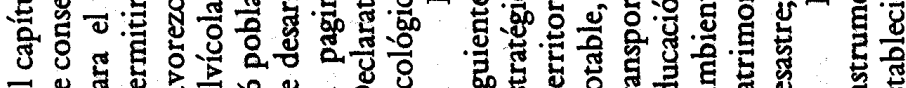

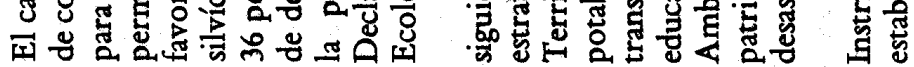


mantenimiento al patrimonio cultural e histórico; continuar la reestructuración de los barrios afectados por los sismos de 1985; impulsar la revitalización del Centro Histórico; y, fomentar el uso de suelo habitacional.

En términos de la estrategia, el programa establece impulsar y consolidar los siguientes elementos de su estructura urbana: un centro urbano que será el Centro Histórico de la Ciudad de México; un subcentro urbano (Chabacano); tres centros de barrio (Santa María la Rivera, Guerrero y Esperanza); y un conjunto de corredores urbanos (Av. de los Insurgentes, Cuauhtémoc, Av. Chapultepec - Fray Servando Teresa de Mier-, Arcos de Belén, Av. Benjamín Franklin, Baja California, Av. Central, Av. Ribera de San Cosme, Puente de Alvarado, Circuito Interior, Av. Paseo de la Reforma, Calzada de Tlalpan y Anillo de Circunvalación).

Según la estrategia de usos de suelo destaca que $60 \%$ de la superficie es mixta, reconociendo la gran heterogeneidad que presenta en su carácter de distrito central de una gran metrópoli. En vialidad propone construir un "par vial ${ }^{\mathrm{n}}$ del eje 1 sur y la línea 9 del metro. Como Zonas Especiales de Desarrollo Controlado (ZEDEC) se proponen las siguientes: Juárez; Roma Norte y Sur; Condesa; Hipódromo Condesa; y Centro. Adicionalmente presenta 11 zonas patrimoniales destacando que dentro del perímetro "A" del Centro Histórico la altura máxima de las edificaciones será de 15 metros o cuatro niveles y 3.5 de intensidad máxima.

\section{iii. Programa Integral contra la Contaminación Atmosférica de la} Zona Metropolitana de la Ciudad de México (PICCA)

El PICCA fue publicado en octubre de 1990, dos años después de haberse implantado el Programa de Inspección y Mantenimiento $(\mathrm{I} / \mathrm{M})$ mediante el cual se verificaba la condición de los vehículos automotores dos veces al año, y un año después de implementarse el programa de contingencia "Un día sin auto", que desde 1989 y hasta 1996 ha resultado ser permanente.

Considerando que alrededor de $\mathbf{7 5 \%}$ de los contaminantes atmosféricos son emitidos por vehículos automotores, el PICCA sigue la tendencia de las anteriores medidas centrándose en aspectos relacionados con la tecnología en vehículos y combustibles mediante la promoción de la producción y consumo de la gasolina sin plomo; la reducción del contenido de azufre en el diesel y en la gasolina; la ampliación de la red de transporte colectivo de metro y trolebús; el reemplazo de los autobuses de Ruta-100 por 3,500 unidades nuevas; la extensión del programa I/M a las unidades de diesel; la conversión de gasolina a gas en los camiones de carga; la instalación de convertidores catalíticos en todos los taxis y colectivos; promover incentivos fiscales y crediticios para que las empresas manufactureras instalen equipo anticontaminante; la sustitución de combustóleos por gas natural en plantas generadoras de energía para reducir la liberación de azufre; la reforestación de Leas periféricas de la ciudad para constituir un gran cinturón verde; y, finalmente, promover la integración sobre la problemática ecológica de la ciudad.

El PICCA estimó que para su quinto año de funcionamiento, en 1995, se reducirían las emisiones contaminantes en relación con 1989 en los siguientes porcentajes: 36\% en monóxido de carbono; $79 \%$ en bióxido de azufre; $26 \%$ en hidrocarburos; $55 \%$ en partículas suspendidas totales; $5 \%$ en dióxido de nitrógeno; y $40 \%$ en plomo.

El PICCA tuvo un presupuesto de más de 3,000 millones de dólares y constituye, incuestionablemente, el esfuerzo más serio y riguroso para reducir la contaminación atmosférica de la capital del país. Sin embargo, se ha concluido que únicamente logró reducir el nivel de contaminación atmosférica del plomo, manteniendo estable, pero por debajo de la norma, los niveles de monóxido de carbono y bióxido de azufre. El bióxido de nitrógeno y las partículas suspendidas totales continúan con magnitudes elevadas, mientras que el ozono presenta altos y crecientes niveles (Garza y Aragón, 1995). En síntesis, a pesar del considerable esfuerzo y los grandes montos de recursos económicos utilizados en el PICCA, la situación ambiental de la urbe está lejos de ser resuelta satisfactoriamente, por lo que tendrán que redoblarse las acciones encaminadas a enfrentarla.

\section{iv. Programas sectoriales}

Para instrumentar los principales objetivos del Programa General se realizan programas sectoriales que guían las principales acciones en materia urbanística, tal como se desprende del título de éstos al inicio del presente acápite. Por razones de espacio, únicamente se describirán de manera sucinta dos de los más recientes.

Programa de revitalización del Centro Histórico. La parte central de la Ciudad de México es una de las áreas coloniales más importantes y antiguas de lasciudades latinoamericanas. Para efectos de este programa, el centro se subdivide en dos perímetros: A y B. El perímetro A tiene una superficie de 3.2 kilómetros cuadrados con 
1,534 edificios catalogados. Abarca la zona que ocupó Tenochtitlan y la superficie de la ciudad española virreinal hasta la guerra de independencia en 1810. El perímetro B, con una extensión de 5.9 kilómetros cuadrados, comprende la superficie de la ciudad hasta finales del siglo XIX. El Programa de Revitalización del Centro Histórico constituye un esfuerzo por resolver la situación de deterioro en que se encuentran la mayor parte de las edificaciones en ambos perímetros mediante la participación de organizaciones sociales, públicas y privadas en el Patronato del Centro Histórico que fue fundado en diciembre de 1991.

El programa crea un fideicomiso en Nafinsa para captar recursos para la restauración de los inmuebles mediante la implementación de un sistema de "Transferencia de Potencialidads, que permite comprar áreas con gran desarrollo potencial en distintas partes del Distrito Federal y canalizar algunos de los recursos obtenidos de su venta posterior para dichas restauraciones (véase Gamboa de Buen, 1994: 203).

Plan de Rescate Ecológico de Xochimilco. Este programa se establece en 1989 para enfrentar la aguda degradación de la zona chinampera de Xochirnilco ante el abandono de las prácticas de cultivo, la disminución del turismo y el impacto de la expansión de la mancha urbana.

El programa abarca una superficie de 1,390 hectáreas, para las cuales se perseguirán las siguientes metas: evitar las inundaciones de la delegación por medio de lagunas de regulación; incrementar la recarga acuífera y preservar los mantos existentes; prevenir mayores hundimientos diferenciales; elevar el número de chinampas dedicadas al cultivo; incrementar la calidad ecológica de lagos y canales; reordenar y controlar los usos de suelo para frenar el crecimiento de la mancha urbana; crear espacios verdes y turísticos en esta zona de la ciudad; buscar instrumentos jurídicos que permitan conciliar los intereses de la población y las autoridades; incrementar la capacidad de la Planta de Tratamiento de Aguas Residuales del Cerro de la Estrella; y controlar los drenajes de la zona montañosa de la delegación.

Un elemento central del programa fue la construcción del Parque Natural de Xochimilco, en una extensión de 318 hectáreas. Con este proyecto se busca darle a la Ciudad de México un parque natural, botánico, histórico, cultural, arqueológico, deportivo, recreativo y de un mercado de pfantas en donde lo predominante sea el contexto ecológico de Xochimilco, evitando al máximo las superficies construidas. En la actualidad este parque está abierto al público y se financia por medio del cobro de boletos de admisión.

\section{v. Programa General de Desarrollo Urbano del Distrito Federal, $19 \%$}

Todo programa de desarrollo urbano debe contener un diagnóstico y un pronóstico de las características esenciales de la ciudad, a partir de los cuales se diseñan sus objetivos, metas, políticas, estrategias e instrumentos. Considerando este planteamiento, en esta sección se realiza un análisis esquemático del Programa General de Desarrollo Urbano del Distrito Federal, 1996 (PGDUDF, 1996), documento que abroga al programa de 1987 anteriormente presentada.

El PGDUDF, 1996, contiene cinco capítulos en su cuerpo de trabajo, más otro adicional en forma de anexo de información gráfica. El contenido de dichos capítulos se ajusta a lo establecido en el artículo 18 de la Ley de Desarrollo Urbano del Distrito Federal de 1996, lo que restringe las posibilidades de enriquecer temática y conceptualmente un ejercicio de este tipo.

El capítulo 1, titulado Fundamentación y Motivación, presenta los antecedentes jurídicos y programáticos, así como el diagnóstico y pronóstico, siguiendo textualmente lo señalado en el mencionado articulo 18. Con esto cumple cabalmente con lo prescrito en la ley, pero renuncia a una estructura de contenido mas coherente, en la cual diagnóstico y pronóstico constituyan el capitulado central del programa.

El diagnóstico, base que fundamenta todo plan, señala correctamente que a finales del siglo Xx la Ciudad de México se encuentra en un cuarto momento de su expansión. Éste se inicia a principios de los años ochenta, cuando la urbe se constituye en el núcleo de un conglomerado que el programa denomina, sin definir, "corona regional megalopolitàna" o "megalópolis de la región centros, aunque técnicamente hablando sería mas adecuado denominarlo subsistema de ciudades de la Ciudad de México. Sea como fuere, esta megalópolis contaba con 20.8 millones de habitantes en 1990, que correspondían a $25.6 \%$ de la población nacional.

El PGDUDF, 1996, señala que la megalópolis eleva su participación en el Producto Interno Bruto nacional (PR) de $42 \%$ en 1970 a $44 \%$ en 1988. Extraña que esta información no esté actualizada con los censos económicos de 1993, así como que no se vincule la dinámica macroeconómica de la metrópoli con su 
crecimiento urbanístico y demográfico, lo cual debería constituir el punto de partida metodológico.

Sin definir los nexos entre el conglomerado megalopolitano con el Distrito Federal, se pasa al diagnóstico de la población y extensión urbana de esta última entidad. En esta parte se introduce otro ámbito de concentración bajo las siglas ZMVM, que en capítulos posteriores se aclara que se trata de la Zona Metropolitana del Valle de México. Conviene aclarar que también se utiliza el concepto de Zona Metropolitana de la Ciudad de México (ZMCM), probablemente como sinónimo, pero técnicamente mas correcto. Adicionalmente, se incluye el concepto de Ciudad de México que, al parecer, se refiere al Distrito Federal.

La ZMVM tiene en 1990 una población de 15.2 millones de habitantes, de los cuales 54.3\% se localizan en el Distrito Federal y $45.7 \%$ en los municipios conurbados del Estado de México. Se estima, adicionalmente, que en 1995 la superficie del área urbana de la metrópoli asciende a 132,576 hectáreas, lo que implica una densidad media de $129 \mathrm{hab} / \mathrm{ha}$. Considerando que la superficie de las Áreas Geoestadísticas Básicas (AGEB's) urbanas de la ZMCM, constituida por las 16 delegaciones del Distrito Federal y 32 municipios conurbados del Estado de México, sumaban 170,572 hectáreas con una densidad de $92.5 \mathrm{hab} / \mathrm{ha}$, se cree necesario revisar las estimaciones del PGDUDF, 1996, pues la extensión del área urbana y su densidad son dos de las variables centrales para la planeación del uso del suelo.

El diagnóstico económico del Distrito Federal se efectúa según su participación porcentual en el PIB y en la Población Económicamente Activa (PEA) nacional. Aunque el análisis macroeconómico es ostensiblemente limitado, permite identificar la clara tendencia a la especialización de la entidad en actividades terciarias .

El diagnóstico finaliza presentando aspectos generales de las finanzas locales; sobre las consecuencias ambientales de la dinámica urbana; del suelo y la vivienda como soportes urbanísticas (en el Distrito Federal existen 5,802 hectáreas baldías que representan $8.9 \%$ de la superficie urbana, $15 \%$ de las viviendas son compartidas y $23.3 \%$ en renta); así como sobre los servicios y el equipamiento.

El pronóstico del PGDUDF, 1996 es únicamente demográfico, sin incluir prospectiva alguna de la estructura macroeconómica y urbana del Distrito Federal. Se estima que la población de la "megalópolis de la región centro" pasará de 20.9 a 35.8 millones de personas entre 1990 y el año 2020, mientras que la población del
Distrito Federal lo hará de 8.2 a 9.0 millones entre esos años. Según los datos preliminares del Conteo de Población de 1995 realizado por el INEGI, el Distrito Federal tiene en ese año 8.8 millones de habitantes, siendo que algunas delegaciones del segundo contorno crecen a tasas elevadas, como Cuajirnalpa con $5.47 \%$ anual entre 1990 y 1995, Iztapalapa con 4.85\%, Contreras con 4.25\%, Tláhuac con $5.83 \%$ y Tlalpan con $5.93 \%$ (véase el cuadro 1). Varias de estas delegaciones aún tienen considerables superficies de terreno no urbanizado y podrían seguir absorbiendo población, por lo que si el Distrito Federal recuperara su crecimiento económico es posibleque supere con amplitud la estimación poblacional del programa.

Sobre las implicaciones de planear una concentración de 35.8 millones de personas en la "megalópolis de la región centro" en el año 2020, el PGDUDF, 1996 señala que “[...] debe corresponder a la capacidad de los recursos naturales y del medio ambiente construido existente, con el fin de procurar un desarrollo sustentable" (Departamento del Distrito Federal, 1996: 30). Se podría agregar que debe guardar también correspondencia con la capacidad financiera y tecnológica del gobierno federal y las autoridades locales, visualizándose que en el futuro previsible no será viable disponer de las inversiones para sufragar los proyectos multimillonarios que tal concentración demandará, de lo cual se deriva la gran dificultad de lograr su desarrollo sustentable. Considerando esta situación, sería recomendable establecer una serie de acciones para frenar el crecimiento de esta superconcentración económica y demográfica, escenario que el programa no se plantea.

El PGDUDF, 1996 analiza la participación del Distrito Federal en la economía nacional en el periodo de 1970 a 1993, pero no incorpora ningún pronóstico económico para la ciudad, lo cual constituye probablemente una de sus principales limitaciones. La información utilizada muestra un considerable declive en la importancia económica del Distrito Federal al reducir su participación en el PIB nacional de $27.6 \%$ en 1970 a $21.5 \%$ en 1992 , lo cual " $[. .$.$] pone en evidencia que las condiciones de una economía$ abierta y globalizada han expuesto a los productores locales a la competencia internacional, lo que ha mermado las ventajas de las economías de aglomeración que en el pasado dieron crecimiento a la economía del Distrito Federal (Departamento del Distrito Federal, 1996:35). Cabría acotar, a este respecto, que la apertura económica ocurre a partir de 1986, cuando México ingresa al GATT, y que ésta, además, no tiene por que mermar las economías de aglomeración de la Ciudad de México. Adicionalmente, la información contradice la 
conclusión anterior sobre la terciarización de la capital del país, puesto que la industria manufacturera mantiene prácticamente invariable su participación en el PBB total nacional al pasar de $24.7 \%$ en 1985 a $24.6 \%$ en 1992 , mientras que los servicios la disminuyen, principalmente los serviciosfinancieros, seguros y bienes inrnuebles, que se desploman de $30.1 \%$ en 1988 a $18.1 \%$ en 1992 . Esto Último explicaría que un elevado porcentaje de la "gran cantidad" de edificios para oficina, comercios, hoteles y restaurantes construidos en los últimos cinco años (Departamento del Distrito Federal, 1996:33) se encuentren desocupados.

En síntesis, el PGDUDF, 1996 no incorpora ningún escenario económico para la ciudad, siendo evidente la necesidad de impulsar la realización de investigaciones rigurosas sobre la dinámica macroeconómica de la megalópolis, la ZMCM y el mismo Distrito Federal.

Con respecto a la prospectiva de la estructura social, los cinco párrafos que constituyen el inciso de tendencias sociales se quedan muy lejos de ser un diagnóstico-pronóstico de las características sociales de la entidad al excluir temas claves como los movimientos sociales urbanos; marginación y pobreza; desempleo, subempleo y ambulantaje; violencia, drogadicción e inseguridad pública; entre otros.

El capitulo I termina con la sección de tendencias territoriales, donde se sintetiza en cinco paginas la situación del medio ambiente y la evolución de la estructura urbana. En una página y media se incorporan las condiciones del medio ambiente, siendo que la crítica situación de la contaminación atmosférica se menciona en sus características más generales en un párrafo de cinco renglones, por lo que se puede decir que es verdaderamente insuficiente, aunque exista un programa específico sobre el medio ambiente cuyas partes centrales debería integrar con la problemática urbanística y demográfica. Finalmente, en la parte correspondiente a la estructuración del espacio urbano se trata Únicamente el problema de la vivienda, sin mencionar el resto de los usos y destinos del suelo y sus magnitudes correspondientes.

En general, las 16 paginas de la parte prospectiva del programa son planteamientos que cubren insuficientemente los elementos económicos, sociopolíticos y urbanísticos que conformarán el futuro de la urbe, haciendo improbable diseñar una imagen objetivo realista y las acciones específicas para alcanzarla.

El capitulo II, titulado Imagen objetivo, presenta, más que una visión totalizada del futuro deseable para la ciudad, los objetivos y las metas del PGDUDF, 1996. Los objetivos particulares son' 13, destacando los planteamientos sobre la regulación del mercado inmobiliario, la distribución "armónica" de la población y la conservación del medio natural. Las metas deberían ser más precisas y expresadas cuantitativamente; pero adquieren también un carácter normativo y reiteran algunos de los objetivos, tales como el acceso más equitativo de la población a la vivienda; creación de una oferta adecuada de suelo; mejorar las condiciones de la estructura vial y estimular la utilización del transporte público; e impulsar la vigencia del programa mediante el diseño de instrumentos de planeación y la participación ciudadana (Departamento del Distrito Federal, 1996:46).

Esta serie de metas normativas son muy loables, pero su carácter general imposibilita la evaluación del programa, para lo cual se requiere además conocer cómo alcanzarlas, esto es, sus instrumentos, materia de un apartado posterior. Adicionalmente, las metas podrían ser contradictorias, como fomentar las actividades productivas y crear empleos, lo que implica promover la dinámica de crecimiento de la ciudad y con ello el número de automóviles y fuentes fijas contaminantes, con lo que se contraviene el propósito de preservar su ecosistema. Lo ideal sería asegurar un flujo de inversión suficiente para preservar el tamaño de la urbe sin imprimirle mayor dinamismo.

La parte neurálgica del PGDUDF, 1996 la constituye el inciso 2 del capítulo $\mathrm{m}$, el cual presenta la estrategia del programa en relación con la estructura urbana, estableciendo las orientaciones y los lineamientos de acción de mediano y largo plazo que deberá contemplar la política de uso del suelo del Distrito Federal. Sorprende, de inicio, que establezca en 9.8 millones de habitantes la población programática para el Distrito Federal en el año 2020, cifra superior a los 9.0 millones presentada en el pronóstico: Sin embargo, como se señaló anteriormente, es muy probable que la primera cifra sea la mas realista.

La clasificación del suelo se ajusta al artículo 30 de la Ley General de Desarrolla Urbano del Distrito Federal, 1996, que señala dos grandes tipos: suelo urbano y suelo de conservación. El suelo urbano comprende 63,382 hectáreas, y el de conservación 615,554 hectáreas, preservando la línea de conservación definida en el programa de 1987. El mantener la superficie de conservación, que es de cardinal importancia para la sustentabilidad del desarrollo de la ciudad, constituye un mérito del nuevo programa. 
La aplicación de las acciones del programa se enmarca en la tipología de suelo urbano señalada en el articulo 31 de la anterior ley, a partir de lo cual se determinan las áreas de actuación: i) con potencial de reciclamiento; $i$ i) con potencial de desarrollo; $i$ ii ) con potencial de mejoramiento; iv) áreas de conservación patrimonial; $\mathrm{y}, \boldsymbol{v})$ áreas de integración metropolitana. Paralelamente, en el suelo de conservación se tienen: î́ áreas de rescate; î̀) área de preservación; $\mathrm{y}$, iii) áreas de producción rural y agroindustrial. Para cada una de estas áreas se presenta el nombre, superficie y ubicación en la trama urbana. Dentro de la estrategia urbanística destacan las propuestas de redensificar áreas con poca población, para recuperar las densidades históricas de $150 \mathrm{hab} / \mathrm{ha}$; fortalecer los subcentros urbanos; promover la protección efectiva de las zonas de conservación ecológica; minimizar los desplazamientos mediante la diversificación de los usos del suelo; completar el equipamiento e infraestructura en áreas deficitarias; diseñar un sistema intermoda coordinado de transporte; continuar con la construcción de los ejes viales troncales; ampliar la red digitalizada de semáforos; completar la red primaria de vialidad; entre las principales. A esto $s$ agrega la identificación específica de áreas de renovación, mejoramiento, conservación y preservación. Ante lo deseable de lograr cristalizar estos planteamientos, sólo cabría reiterar la conveniencia de establecer las prioridades para la ejecución de los proyectos y su viabilidad financiera.

El capitulo IV, titulado Acciones Estratégicas, de cinco paginas de extensión, contrasta notablemente con lo detallado del anterior, limitándose básicamente a sintetizar las propuestas de los capítulos II y III. En su primer acápite plantea la necesidad de articular las acciones de política urbana en el contexto metropolitano y megalopolitano. Para determinar su viabilidad sería conveniente establecer propuestas específicas y revisar las causas del fracaso de la antigua Comisión de Conurbación del Centro, para evitar caer en falsas soluciones de tipo administrativo. En esta dirección, sería más recomendable explorar la viabilidad política de constituir un gobierno de cipo metropolitano o instancias ejecutivas de ese nivel. Del resto de las acciones presentadas en este capítulo, ya se ha señalado la conveniencia de jerarquizarlas y establecer fuentes y montos de los recursos financieros requeridos.

El cuerpo principal del PGDUDF, 1996 termina con el capítulo $\mathrm{V}$, que se denomina Instrumentación, esto es, la parte que se refiere a cómo lograr alcanzar la imagen objetivo y las metas trazadas. En esta dirección, el programa establece los siguientes

instrumentos: $i$ ) de planeación; $t i$ ) de regulación; iii) de fomento; iv) de control; $\mathrm{y}, \boldsymbol{v}$ ) de coordinación. En la parte de los instrumentos de planeación se limita a señalar que deberán realizarse los programas delegacionales y programas parciales, donde $s$ detallarán las acciones a efectuar en las áreas de actuación. Habría que agregar que el artículo 17 de la Ley de Desarrollo Urbano del Distrito Federal señala la existencia de programas sectoriales y programas anuales de desarrollo urbano, por lo que por ley se tiene un ambicioso conjunto de programas que no será fácil realizar adecuadamente.

En el marco de los instrumentos de regulación se establece la necesidad de modernizary simplificar la zonificación, es decir, las disposiciones existentes para regular los usos del suelo. Esto se tendrá que realizar en los programas delegacionales en los cuales se deberá determinar a detalle el tipo e intensidad de usos de suelo en el territorio de cada delegación. Los instrumentos de fomento serían la concertación e inducción de actividades a realizar por los sectores social y privado, así como promover la desregulación y simplificación administrativa. Los instrumentos de control, por su parte, se centrarían en la orientación territorial del gasto público, el control de uso del suelo y la acción pública ante los tribunales competentes para garantizar el control social de la planeación urbana. Finalmente, los instrumentos de coordinación estarían constituidos por una serie de comisiones intersecretariales, así como por la Comisión Metropolitana de Asentamientos Humanos, la cual se procurará fortalecer.

En esta última parte del programa, como se ve, se delinean los instrumentos necesarios para implementarlo, sin concrerizarlos. Sería conveniente que también se hubiesen detallado los requerimientos financieros del programa y los tiempos para la realización de los programas delegacionales, sectoriales y anuales, pues de esto depende la posibilidad real de alcanzar la imagen objetivo propuesta para la urbe.

En fin, a pesar de las limitaciones que presenta el PGDUDF, 1996, éste supera notablemente la calidad técnica, analítica, conceptual e instrumental de sus antecesores, por lo que constituye un avance en la evolución de la planeación urbana de la Ciudad de México. 
Este programa consta de 12 capítulos que no presentan un ordenamiento lógico según las partes clásicas de todo plan o programa: antecedentes y conceptualización, diagnóstico, pronóstico, objetivos, metas, estrategias e instrumentos. En un intento de organizar mas coherentemente su estructura, se podrían integrar los capítulos I, II, V, VI y VII en una primera parte de antecedentes y conceptualización; los capítulos m y IV conformarían el diagnóstico; el vin las metas; el IX la estrategia; y, finalmente, el $\mathrm{X}, \mathrm{XI}$ y $\mathrm{XIl}$ las cuestiones instrumentales. De inicio se observa la ausencia de un pronóstico, o escenarios futuros de los determinantes y niveles de contaminación atmosférica en el Valle de México en el corto, mediano y largo plaza.

Antecedentes y conceptualización. Abatir los niveles de contaminación atmosférica del Valle de México es una exigencia social, por lo que “[...] para que los procesos vitales que mantienen el funcionamiento y generan el crecimiento de la Zona Metropolitana del Valle de México (ZMVM) no sigan deteriorando la calidad del aire, es necesario iniciar de inmediato un gran número de acciones eficaces y complementarias [... $]^{\prime \prime}$, tal es el planteamiento inicial del capitulo I, titulado, Presentación: los motivos y los retos (DDF, etal., marzo de 1996:9). Estos "procesos vitales" no pueden ser otra cosa que el crecimiento económico y demográfico de la urbe, que implica el incremento de los vehículos automotores y del número de establecimientos industriales, comerciales y de servicios, que constituyen las fuentes de la contaminación del aire. De esta suerte, lasvariables independientessobre las que el programa debería actuar son dinámicas (flujos), por lo que sería verdaderamente limitado considerarlas estáticas (stocks). No obstante, estas variables independientes, junto con las condiciones meteorológicas, determinan los niveles de contaminación atmosférica, por lo que el control de su crecimiento debería constituir el punto de partida del PMCAVM, pero del análisis que sigue se desprende que esto no ocurre, constituyendo su gran limitación. El concepto de ZMVM tampoco es explicado, pero aquí se onsidera que se refiere a la Zona Metropolitana de la Ciudad de México (ZMCM), tal como es comúnmente definida en los estudios al respecto.

Sea como fuere, èl propósito general del programa es “[...] proteger la salud de la población que habita la zona metropolitana de la capital de la República, abatiendo para ello de

manera gradual y permanente los niveles de comtaminación atmosférica" (DDF, et d., marzo, 1996:9). Mespecificamente, uno de los propósitos del programa "[...] es enfatizar que los esfuerzos de la sociedad y de los gobiernos deben ser encauzados a partir de conceptos de mayor integración y alcance, que se reconozcan dentro de un proyecto de ciudad en el sentido más ámplio del término" (DDF, et al., marzo de 1996:11).

El procedimiento metodológico desarrolladose apoya en dos ejes básicos: $\hat{\imath}$ ) "[...] revisión a fondo de las causas de la contaminación [...]" y "[...] elaboración de una tipología de las variables consideradas"; y, ii ) determinación de metas, estrategias e instrumentos. Siendo tan acotado el problemá de la contaminación atmosférica, el PMCAVM es muy riguroso y realista at especificar nítidamente el vínculo entre esos dos ejes básicos y establecer, de inicio, cuatro metas generales (DDF, et al., marzo de 1996:13):

- Industria limpia: reducción de emisiones en la industria y servicio.

- Vehículos limpios: disminución de emisiones por kilómetro.

- Nuevo orden urbano y transporte limpio: regulación del total de kilómetros recorridos por vehículos automotores.

- Recuperación ecológica: abatimiento de la erosión.

Sin embargo, la "revisión a fondo de las causas de la contaminación" es verdaderamente insuficiente. Además, el análisis de las principales fuentes de contaminación es estático, esto es, considera su magnitud al nivel que se encuentran en la actualidad, sin tomar en cuenta su crecimiento futuro.

Para alcanzar estas metas generales, el PMCAVM presenta nueve acciones estratégicas: $i$ ) mejoramiento e incorporación de nuevas tecnologías en la industria y los servicios; $i$ i) mejoramiento e incorporación de nuevas tecnologías en vehículos automotores; $i$ ii) mejoramiento y sustitución de energéticos en la industria y los servicios; iv) mejoramiento y sustitución de energéticos automotrices; $\boldsymbol{v}$ ) oferta amplia de transporte público seguro y eficiente; $v \boldsymbol{\imath}$ ) integración de políticas metropolitanas (desarrollo urbano, transporte y medio ambiente); vii) incentivos económicos; viii) inspección y vigilancia industrial y vehicular; $\mathrm{y}, i x$ ) información y educación ambientales y participación social (DDF, et al., mano de 1996:13). 
Independientemente de que las anteriores consideraciones sean más exactamente metas específicas que estrategias, quedaría por considerar cuáles serían las medidas concretas para alcanzar los objetivos y las metas del programa, así como la viabilidad de su aplicación.

El capitulo II, Normas de calidad del aire y salud ambiental, señala que las siguientes normas de calidad del aire existentes en México se establecieron siguiendo los estándares adoptados en otros países del mundo: ozono $(\mathrm{O}),$,0.11 partes por millón (ppm) en una hora; bióxido de azufre (SO;), 0.13 ppm en 24 horas; bióxido de nitrógeno (NO;), $0.21 \mathrm{ppm}$ en una hora; monóxido de carbono (CO), 11 ppm en 8 horas; partículas suspendidas totales (PST) 260 $\mu \mathrm{g} / \mathrm{m}^{3}$ en 24 horas; partículas fracción respirable (PM10), $150 \mu \mathrm{g} / \mathrm{m}^{3}$ en 24 horas; y plomo $(P b), 1.5 \mu \mathrm{g} / \mathrm{m} 3$ como promedio aritmético en 3 meses (DDF, $\boldsymbol{e}$ t al., marzo de 1996:17)

En este capítulo se describen las características generales de los niveles de contaminación y su impacto en la salud de la población, principalmente en afecciones pulmonares, cardiovasculares o cancerígenas. El PMCAVM en forma muy objetiva señala, sin ambages, las grandes limitaciones que se tienen para determinar el impacto de la contaminación en la salud por la escasa investigación existente en la materia, afirmando que “[...] no existen los recursos ni la infraestructura para realizar estudios epidemiológicos, toxicológicos y de exposición [...]”, así como que “[...] los estudios de exposición real a contaminantes se encuentran poco desarrollados sin que a la fecha se cuente con un acervo significativo de información al respecto" (DDF, et al., marzo de 1996:17 y 18).

Desconcierta que el capítulo v, titulado Antecedentes y esfuerzos institucionales en la lucha contra la contaminación atmosférica, se localice a la mitad del programa, pero en este análisis se ha situado en los antecedentes y conceptualización. Presenta en forma por demás sucinta a su antecesor, el Programa Integral contra la Contaminación Atmosférica en la Zona Metropolitana de la Ciudad de México (PICCA), el cual fue publicado en octubre de 1990, así como al Programa Hoy No Circula. Con el PICCA, que se implementó con una inversión total de 2,333 millones de dólares, según el PMCAУM “[...] se consiguieron reducciones significativas en las emisiones de bióxido de azufre, plomo, partículas y monóxido de carbono, mientras que en el caso del ozono se frenó su tendencia ascendente" (DDF, et al., marzo de 1996:112).

El PICCA constituyó incuestionablemente un programa complejo y realmente operativo, el cual se planteó para sa quinto año de ejecución -1995- reducir las emisionescontaminantes ea los siguientes porcentajes: $36 \%$ en monóxido de carbono; $79 \%$ en bióxido de azufre; $26 \%$ en hidrocarburos; $55 \%$ en partículas suspendidas totales; $5 \%$ en dióxido de nitrógeno; y $40 \%$ en plomo (Secretariado Técnico Intergubernamental, 1990:48). Hubiera sido conveniente que el PMCAVM evaluara cuantitativamente las metas anteriores del PICCA, pues es improbable que las alcanzara en su totalidad e importaría mucho determinar las causas y tratar de resolverlas. Esto sería verdaderamente significativoconsiderandoque en México no es fácil articular dos programas realmente operativos, por lo que su éxito promovería los ejercicios de planeación en el país.

El capítulo vi, sobre el Marco conceptual para la integración de políticas ambientales urbanas, es la parte central de los antecedentes y conceptualización. De inicio se plantea renovar y enriquecer el marco conceptual de las políticas y acciones diseñadas para enfrentar los problemas ambientales. En esta dirección, señala que es “[...] preciso explorar un nuevo marco conceptual fundado en una reflexión que busque no sólo las verdaderas causas estructurales de los problemas ambientales, sino que vaya más allá en la identificación tanto de los elementos como de los mecanismos que definen y operan los complejos sistemas urbanos" (DDF, et al., marzo de 1996:117). El fin último del diseño de un marco metodológico es articular los elementos que garanticen un desarrollo urbano sustentable, objetivo fundamental del PMCAVM para el caso de la Ciudad de México.

Desarrollar tal marco conceptual queda muy lejos de las posibilidades del programa, pero es muy positivo que considere la necesidad de hacerlo. Uno de los aspectos que requiere de más completas elaboraciones es la naturaleza de la estructura urbana de la metrópoli, su transformación en un conglomerado de tipo megalopolitano y sus perspectivas macroeconómicas futuras, pues el PMCAVM sólo introduce algunas de las manifestaciones urbanas más evidentes y convencionales (economías de aglomeración, sistema de bienes públicos, externalidades, etc.). Sin embargo, parte de una premisa de cardinal importancia en la práctica de las acciones urbanas: "la política ambiental debe ser expresada a través de la política urbana y operada a través de la dinámica espacial y territorial de la ciudad [...]” (DDF, et al., marzo de 1996:121). Este elemental planteamiento conceptual no ha sido fácil de seguir en la 
práctica de la planeación urbana en México, y para no ir más lejos basta mencionar que el PMCAVM se elaboró al menos un año antes que el Programa General de Desarrollo Urbano del Distrito Federal, 1996, con el cual debería estar estrechamente coordinado. Esto probablemente no ocurre por consideraciones institucionales, pero también por dificultades conceptuales que se tendrán que resolver.

Una limitación conceptual importante del PMCAVM es que no logra analizar satisfactoriamente las denominadas "verdaderas causas estructurales de los problemas ambientales" (DDF, et al., marzo de 1996:117). Adicionalmente, al intentar articular la política ambiental con el desarrollo urbano lo hace con base en ciertas sobresimplificaciones siguiendo la mecánica de los factores locacionales tradicionalescomo, por ejemplo, el señalamiento de que para "[...] encauzar a la metrópolis hacia un futuro sustentable, es preciso promover su productividad y fortalecer sus ventajas competitivas", para lo cual sería óptimo "[...] contar con mano de obra altamente calificada en los lugares donde se le necesita, tener acceso a nuevas tecnologías y procesos de producción mas limpios y eficientes, contar con la información requerida acerca de las necesidades específicas de los consumidores de diferentes lugares, contar con una infraestructura de buena calidad y amplia cobertura [...]" (DDF, et al., marzo de 1996:122). Con todo esto sería posible "garantizar la fortaleza y el dinamismoeconómico de la metrópolis".

Este planteamiento introduce una pregunta cuya respuesta debe constituir el centro del debate sobre las perspectivas futuras de la Ciudad de México: ¿ En las condiciones actuales es posible que la urbe logre un desarrollo sustentable si continua su proceso de crecimiento económico y su transformación en el centro de una región polinuclear de corte megalopolitano?

De la respuesta a esta interrogante dependerá la posibilidad de alcanzar el propósito general que plantea el PMCAvM en su capítulo VII, esto es, lograr que "...cada vez se tengan menores niveles de contaminantes por día y menos contingencias por año" pues, "[...] en última instancia el propósito general es sin duda el de cuidar la salud de los habitantes del Valle de México y salvaguardar la de las generaciones futuras" (DDF, et d., marzo de 1996:129). Para intentar lograr este propósito el programa plantea el siguiente objetivo sustantivo: reducir los niveles de contaminación del valor medio actual de 170 IMECAS a 140-150 en el año 2000, mediante el abatimiento de $50 \%$ de las emisiones de hidrocarburos, $40 \%$ de Óxidos de nitrógeno y $45 \%$ de partículas suspendidas de origen antropogénico (DDF, $\boldsymbol{e}$ t al., marzo de 1996:130). En este trabajo se establece la hipótesis de que esto es inviable, pues no se considera la dinámica de crecimiento de la Ciudad de México en términos del aumento en el número de automóviles, de la mancha urbana, de la población y de las actividades económicas, etcétera, ni su transformación en un conglomerado megalopolitano que implicará el deterioro en cadena de los ecosistemas que conforman los valles de las ciudades de Puebla, Toluca, Cuernavaca y Querétaro, principalmente (véase Gustavo Garza y F. Aragón, 1995:62).

Diagnóstico de la calidad del aire. El diagnóstico debe proporcionar la situación real que se intenta modifica?.. Para el caso del PMCAVM se esperaría que presentara una radiografía lo mas pormenorizada posible de dos conjuntos de elementos: $\boldsymbol{i}$ ) los factores determinantes de la contaminación o, en sus propios términos, "las verdaderas causas estructurales de los problemas ambientales", y ii) el tipo y niveles de los contaminantes. Sobre lo primero el capítulo III del programa $s$ limita a enlistar en media cuartilla las condiciones meteorológicasque contribuyen a agravar la severidad de los niveles de contaminación en la ciudad y a sintetizar los elementos del segundo conjunto. Cabría mencionar sobre esto último que si bien constituye un diagnóstico riguroso de la situación de la calidad del aire, los niveles de los contaminantes no se presentan con sus valores absolutos, lo cual es necesario para evaluar posteriormente las reducciones planeadas.

A pesar de la complejidad que reviste el análisis de los principales contaminantes, el elemento central del diagnóstico deberían ser los factores determinanteso causas de la contaminación. Sobre esto el PMCAVM menciona las tecnologías de los automotores y de las unidades económicas, así como las características de la estructura urbana, los modos del transporte y los kilómetros recorridos por los vehículos (DDF, et al., marzo de 1996:45). El problema es que sólo se mencionan y no se realiza el diagnóstico correspondiente. Adicionalmente, éstos constituyen las causas inmediatas, pero los factores históricamente estructurales son aquellos que explican la dinámica económica, demográfica y urbanística de la metrópoli, tales como la concentración secular de la inversión pública federal, constituir el principal mercado nacional, ser centro de los poderes de la unión, concentrar los principales servicios al productor $\mathrm{y}$, en general, ser el principal espacio para la concentración del capital en el país. Mientras no exista una política urbana y regional capaz de neutralizar el proceso de conformación de una densa megalópolis en el centro del país, ceteris paribus, el 
problema de los altos niveles de contaminación atmosférica en el Valle de México es insoluble.

Sin embargo, si las actuales acciones tienen un éxito razonable, pueden aminorar la gravedad del problema Según el diagnóstico del capitulo $\mathrm{m}$, éstas deben centrarse en los vehículos automotores que emiten a la atmósfera $71 \%$ de los óxidos de nitrógeno y $54 \%$ de los hidrocarburos, los dos principales precursores del ozono. A este respecto, en el capítulo IV, Usuarios de la cuenca atmosférica, se menciona lo socialmente injustificable de la preeminencia del automóvil privado, medio en el que se realiza $25 \%$ de los viajes diarios, y que es responsable de mas de $50 \%$ de las emisiones contaminantes producidas por el sector transporte (DDF, et al., marzo de 1996:95).

Las chatro metas generales. Mientras el diagnóstico presenta las características de la situación de los niveles de contaminación y de las fuentes que los producen, las metas establecen los cambios que se pretenden lograr para solucionar o reducir el problema. Éstas pueden plantearse en forma cualitativa y cuantitativa, así como ser generales y específicas. El PMCAVM sólo establece en su capítulo VII (Metas), de diez renglones de texto y un par de gráficas presentadas en capítulos anteriores, las cuatro metas generales de tipo cuaiitativo presentadas al principio de esta sección: i) industria limpia; $i i)$ vehículos limpios; iii) transporte eficiente y nuevo orden urbano; y, iv) recuperación ecológica (DDF, et al., manzo de 1996:134). Por la peculiar estructura del programa, las metas específicas y su cuantificación se presentan posteriormente en su capítulo $\mathbf{x}$.

La instrumentación: estrategia, metas, acciones y financiamiento. La instrumentación es el momento de la verdad en la planeación, pues debe establecer cómo y con qué alcanzar las metas propuestas. El capítulo $\mathrm{X}$ del PMCAVM, titulado Estrategias, de una pagina y media de extensión, combina instrumentos de regulación e incentivos para proponer las siguientes "estrategias":

- Mejoramiento e incorporación de nuevas tecnologías en la industria y los servicios.

- Mejoramiento e incorporación de nuevas tecnologías en vehículos automotores.

- Mejoramiento y sustitución de energéticas en la industria y los servicios.

- Mejoramiento y sustitución de energéticos automotrices.

- Oferta amplia de transporte público seguro y eficiente.
- Integración de políticasmetropolitanas(desarrollourbano, transporte y medio ambiente).

- Incentivos económicos.

- Inspección y vigilancia industrial y rehicular.

- Información y educación ambientales y participación social.

Las anteriores'estrategii* son mas bien metas específicas, pues más que referirse al cómo alcanzar las metas establecidas, las desagrega en sus componentes principales.

La amalgama entre metas y estrategias, así como lo esquemático e insuficiente de su planteamiento en los dos capítulos anteriores, se resuelve en buena medida en el capítulo $\mathrm{x}$, que lleva por título Construcción, financiamiento y alcance del programa $\mathrm{El}$ enigmático sustantivo'construcción* que lleva su título, se refiere a la estructuración de una serie de 95 instrumentos, acciones y proyectos que ordena en 15 grupos (véase, DDF, et al., marzo de 1996:141-142). No disponiendo de espacio para transcribirlos, se puede señalar que los grupos número $1,3,7$ y 9 son de naturaleza normativa; los 4, 5, 6 y 10 de incentivos o desincentivos; y $\operatorname{los} 2,8$, $11,12,13,14$ y 15 son acciones de tipo urbano. De esta forma, el PMCAVM intenta articular la política urbana can la ambiental.

Las páginas que van de la 145 a la 212 constituyen la parte neurálgica del programa, pues en ellas se especifican las anteriores 95 acciones (se enlistan 94), según su objetivo, descripción y meta cuantitativa y/o cualitativa. Estas se agrupan bajo las cuatro netas generales planteadas y, por razones de espacio, sólo se sintetizarán algunas de las más relevantes.

Se tiene, en primer lugar, las acciones relacionadas con la primera meta general de Industria Limpia: $\imath$ ) establecer normas més estrictas para reducir en el año 2000 la emisión industrial de óxidos de nitrógeno, bióxido de azufre y partículas en, aproximadamente, 4,500, 14,500 y 1,800 toneladas, en ese orden; $i$ i) establecer en 1996 una nueva normatividad para el almacenamiento, la elaboración y el uso de Compuestos Orgánicos Volátiles (COV) como pinturas, tintas, solventes, etc., con lo que se estima disminuir su emisión en 134,000 toneladas iii) promulgar normas de reconvención tecnológica para la distribución y el uso del gas licuado de petróleo, para reducir sus emisiones de hidrocarburos en alrededor de 95,670 toneladas al año; $\boldsymbol{i} \boldsymbol{v}$ ) elaborar normas industriales de observancia voluntaria con limites más estrictos para la emisión de $N O x$ y $\mathrm{CO}$, con lo que se intenta bajarla a partir de 1996 en 6,600 y 6,900 
toneladas al año, respectivamente; $v$ ) instalación de quemadores con baja emisión de $N O x$ en la unidad 4 (1996) y en las unidades 1, 2 y 3 (1997) de la Termoeléctrica Valle de México, así como sustitución de las unidades de generación de la termoeléctrica Jorge Luque para que cumplan con la normatividad ambiental que entrará en vigor en 1998, con lo que se podrían emitir $\mathbf{6 , 6 0 0}$ toneladas al año menos de NOx. A este tipo de medidas normativas se le agregan otras de incentivos económicos, como el diseño de una nueva estructura de precios para los combustibles con objeto de promover la utilización de los mas limpios; redefinir losincentivosfiscales para el uso de mejores tecnologías de control de emisiones, ampliándolos a exenciones arancelarias para equipo que no se fabriquen en el pais, así como créditos para financiarlos, entre los principales (véase, DDF, et al., marzo de 1996:145-156).

El segundo conjunto de medidas corresponde a la meta general de Vehículos Limpios: i) actualización del programa "Hoy No Circula ${ }^{\mathrm{n}}$ para estimular la circulación de automotores poco contaminantes, con lo que se espera disminuir en cerca de 1,350 toneladas al año los $N O x, 5,250$ los $\mathrm{HC}$ y en 71,092 el $\mathrm{CO}$ provenientes de los vehículos en circulación; $i$ i) establecer normas sobre las emisiones evaporativas de gasolina en los automotores para verificar la hermeticidad del sistema de distribución de combustible, con lo que se podrían emitir $\mathbf{3 5 , 0 0 0}$ toneladas menos de hidrocarburos; iii) actualizar la normatividad de los vehículos en circulación, a- diesel y nuevos, según avances tecnológicos de la industria automotriz, con lo que se estima reducir en 11,195 toneladas al año los $N O x$, en 122,863 los $H C$, en 781,153 el CO y en 5,301 las PST; iv) desarrollar permanentemente el programa de verificación vehicular, para lograr la medición y control del total de emisiones contaminantes y bajarlas en 3,680 toneladas al año las de $N O x$, en 20,026 las de $H C$ y en $\mathbf{2 8 6 , 2 0 7}$ las de $\mathrm{CO}$; v) eliminación, en el segundo semestre de 1996, de los componentes tóxicos y reactivos de las gasolinas para disminuir en 16,400 toneladas al año los hidrocarburos; $v i$ ) supresión progresiva del azufre en la gasolina para extender la duración de los convertidores catalíticos y reducir en 6,800 toneladas al año la emisión de bióxido de azufre. A estas medidas se suman otras relacionadas con el diseño de una política de largo plazo sobre los precios relativos de los combustibles, auditorías permanentes a los centros de verificación, incentivosfiscales para la renovación del parque vehicular, así como fijar un sobreprecio de 3 centavos a las-gasolinas para financiar el
Fideicomiso Ambiental de la ZMVM (véase DDF, et al, marzo de 1996:157-174).

En tercer lugar se tiene la meta general de un Nuevo Orden Urbano y Transporte Limpio, con un conjunto de 38 acciones referidas a mejorar la oferta de un transporte público seguro y eficiente; integrar las políticas urbanas con las ambientales; establecer un conjunto de estímulos económicos para alentar la participación empresarial en proyectos ecológicos; así como diseñar una estrategia de información y educación ambientales y participación social (véase DDF, et d., marzo de 1996:175-203). Este conjunta de medidas no presenta metas cuantitativas en la reducción de los contaminantes, por lo que se remite al lector interesado a consultarlas en el PMCAVM. Algunas de estas revisten gran complejidad en términos de su ejecución, tales como la conformación de 10 empresas privadas concesionarias del transporte de autobuses en sustitución de la Ruta100; la ampliación de la red del metro; la construcción de trenes eléctricos de alta calidad, como el proyectado entre Santa Mónica y el Palacio de Bellas Artes; la modernización completa del sistema de gestión del transito; el establecimiento de un sistema permanente de monitoreo de uso del suelo y protección de la reserva ecológica; la conclusión de pasos a desnivel en el circuito interior y en el periférico; un programa de largo plazo de trenes radiales entre la Ciudad de México y las de Toluca, Pachuca, Puebla, Cuernavaca y Querétaro, que se ubican en su área de influencia inmediata; entre las principales.

En cuarto sitio se encuentra la meta general de la Recuperación Ecológica, en la cual se tienen 12 acciones encaminadas básicamente a procurar la recuperación lacustre de Tláhuac, Texcoco, Xochimilco y Zumpango, así coma la reforestación de las sierras de la entidad y de sus áreas verdes urbanas mediante la plantación de 39.5 millones de plantas (véase DDF, et d., marzo de 1996:204212)

Mediante la materialización de este ambicioso conjunto de acciones que cubren sus cuatro metas generales, el PMCAVM estima mejorar la calidad del aire de la Ciudad de México de manera muy significativa. En una serie de cuadros entre las paginas 216 a la 231, presenta la reducción estimada por año y tipo de contaminante de cada una de las 94 acciones establecidas. La reducción de las emisiones en toneladas anuales entre 1996 y el año 2000 sería la siguiente: 53,577 de $N O x$, que representan $41.6 \%$ del total actual. 516,823 de HC, que constituyen 50.4\% menos; 22,034 de SO [SGGM1] 2 , que implican una disminución de 48.5\%; 1628,820 de CO, 
que significan una baja de 69.0\%; y 203,564 de PST que posibilitarían una mejora de 45.1 por ciento. En síntesis, el PMCAVM se plantea reducir los principales contaminantes atmosféricos del Valle de México en porcentajes que varían entre 40 y $70 \%$, lo que incuestionablemente sería un gran logro. Para alcanzarlo, sin embargo, se requieren cuantiosos financiamientosque se estiman en 10,575 y 2,874 millones de dólares de inversión pública y privada, respectivamente (DDF, et al., marzo de 1996:231).

Como parte complementaria, el capítulo XI sintetiza las características del Programa de Contingencias Ambientales, cuyas fases I y II se activan cuando se alcanzan 250 y 350 puntos IMECAS, en ese orden. El capítulo XI, último del programa, hace una reflexión final sobre las medidas radicales que habría que tomar al tener que paralizar al sector transportes y a toda la actividad económica para reducir un nivel de contaminación de 250 a valores de entre 100 y 140 IMECAS.

El PMCAVM constituye un esfuerzo riguroso para establecer una serie de políticas y acciones que permitan abatir significativamente los niveles alcanzados por la contaminación atmosférica en el Valle de México, destacando particularmente que es un programa operativo de aplicación real que contrasta con los intentos indicativos que caracterizan la planeación sectorial en México. No obstante, como todo ejercicio de planeación, es perfectible, por lo que sería conveniente que se continuara desarrollando para que fuera posibleavanzar en la conceptualización de la articulación entre lo ambiental y las cuestiones urbanas, en una más rigurosa aplicación de la teoría de la planificación y, principalmente, para incluir un ejercicio prospectivo de los determinantes y fuentes inmediatas de la contaminación atmosférica en la Ciudad de México.

\section{e. Normas urbanísticas}

Las normas son procedimientos jurídicos formalmente expresados por órganos institucionales legales para regular las actividades de la población en un tiempo y lugar determinado. En el Distrito Federal existe un conjunto de normas jurídicas, administrativas y urbanas que regulan su crecimiento. Por la naturaleza de este trabajo, interesa señalar las siguientes normas de tipo urbanístico: i. Normas técnicas complementarias para el área urbana del Distrito Federal (DO, 16 de julio de 1987; modificaciones, 21 de diciembre de 1989).

ii. Normas técnicas complementarias para el área de conservación ecológica del Distrito Federal (DO, 16 de julio

iii. Usos y destinos para el área de conservación ecológica (DO, 29 de naviembre de 1982; modificaciones, 16 de julio de 1987).

iv. Tabla de usos de suelo (DO, 21 de septiembre de 1989; modificaciones, 29 de julio de 1891).

v. Establecimiento de 31 Zonas Especiales de Desarrollo Controlado (DO, 14 de julio de 1988).

La normatividad que regula el uso del suelo es central para la planificación urbanística. El Distrito Federal cuenta con los siguientes instrumentos de operación que norman el uso del suelo: la carta urbana de zonificación secundaria de los programas parciales delegacionales, la tabla de usos de suelo; las normas complementarias, el reglamento de zonificación y el reglamento de construcciones. Los programas parciales y los reglamentos ya fueron descritos, faltando únicamente describir la tabla de usos del suelo y las normas complementarias.

\section{i Tabla de uso y densidad del suelo}

Al solicitar construir en un predio, a éste se le ubica en las cartas urbanas para determinar qué usos de suelo tiene permitidos. Una vez verificado y aceptado, se recurre a la Tabla de Usos del Suelo para ver qué requisitos urbanísticos generales debe cumplir. Estas tablas se adjuntan en los planos de usos de suelo de los programas parciales de cada delegación en forma matricial, teniendo como columnas los tipos de zonas secundarias y como renglones la clasificación de usos de suelo. Al interior de la matriz se señala si el uso solicitado está permitido, condicionado o prohibido. Por ejemplo, las zonas habitacionales se subdividen en cinco tipos según se permita una densidad de 50,100,200,400 y 800 habitantes por hectárea en lotes de 125 a $\mathbf{1 , 0 0 0}$ metros cuadrados. En estas zonas prácticamente no se permite establecer actividades industriales y de servicios, que tendrán que localizarse en zonas mixtas, así como en los centros y subcentros urbanos (véase programas parciales delegacionales). 


\section{ii. Nommas técnicas complementarias}

El 16 de julio de 1987 el Diario Oficial de la Federación expidió una serie de normas técnicas complementarias con requisitos adicionales a los que presenta la tabla de usos de suelo. Estas normas complementariassu subdividen en los siguientes rubros: aclaratorias, obligatorias, opcionales de estímulo y desarrolloe informativas. Por brevedad, se resumen las principales normas obligatorias.

La primera norma obligatoria establece que la separación en metros entre edificaciones de alta o media intensidad en colindancia con aquellas de baja intensidad, deberá ser de $15 \%$ de la altura máxima del edificio colindante para garantizar el "asoleamiento" de las construcciones de baja densidad (DO, 16 de julio de 1987:87).

La segunda norma reduce la intensidad de la construcción de los predios menores a mil metros cuadrados que se localizan en zonas señaladas con una intensidad de 7.5. Se presenta una tabla en que dicha intensidad se reduce de 3.5 a 7.3, dependiendo si el lote es menor de 250 metros cuadrados o si se encuentra entre 750 o 1,000 metros cuadrados (DO, 16 de julio de 1987:88).

En tercer lugar se tiene la regulación de las áreas libres de construcción en cada predio, que van de 20 a 30\% según sean lotes iguales o menores de 500 o mayores de 501 metros cuadrados. Una cuarta norma señala que en las zonas habitacionales con densidad de 50 a 200 habitantes por hectárea (claves H05, H1 y H2), la altura máxima de la construcción será de 9 metros sobre el nivel de la banqueta.

Finalmente, las normas informativas enfatizan la necesidad de contar con la constancia de zonificación antes de realizar cualquier trámite o acción inmobiliaria.Señalan, adicionalmente, los requisitos a cubrir en las áreas de conservación ecológica y la existencia de normas adicionales para algunas zonas especiales de la ciudad.

\section{iii. Las Zonas Especiales de Desarrollo Controlado (ZEDEC)}

El Programa General de Desarrollo Urbano del Distrito Federal, 1987-1988, crea a las ZEDEC como una herramienta adicional para controlar el uso de suelo. Con este instrumento se planea tener un mayor control para lograr los objetivos específicos en materia de desarrollo urbano, rural, medio ambiente y del patrimonio arquitectónico (DDF, 1987:117).
Las ZEDEC constituyen programas específicos que agregan un mayor detalle a los programas delegacionales, para lo cual utilizan cartografía a escala 1:2,000 que permite llegar a propuestas a nivel predio para controlar, fomentar o modificar determinados usos del suelo. Hasta 1993 se habían autorizado 22 ZEDEC y estaban en proceso de concertación otras 17 (véase, Gamboa de Buen, 1994:214215). A fines de 1995 existían 27 ZEDEC autorizadas, pero la Ley de Desarrollo Urbano del Distrito Federal de 1996 las convierte en programas pardales para eliminar los riesgos de amparo judicial contra sus lineamientos.

Prospectiva y normatividad urbana de la ciudad de México

Las proyecciones de población del AMCM para 1990 hasta antes de conocer los resultados del censo de ese año, estimaban que tendría alrededor de 19.8 millones de habitantes, bautizándola según esa cifra como "la más grande del mundon ${ }^{n}$. Se ha visto en el inciso 1 de este trabajo que la población, según los resultados censales finales de 1990, fue de 15.8 millones, agregando 15 municipios mexiquenses a los 17 que formaban su área metropolitana en 1980 (véase el cuadro 1). Las estimaciones existentes hasta antes de aparecer el censo de 1990 consideraban que el AMCM tendría 23.5 millones de habitantes en el año 2000 y 26.7 en el 2010 (véase el cuadro 5).

Sin embargo, el AMCM experimentó una significativa disminución de su tasa de crecimiento demográfico en los años ochenta, debido fundamentalmente a la profunda crisis económica nacional, principalmente de 1982 a 1988 (véase G. Garza, 1991). A partir de sus 15.8 millones de habitantes en 1990, se han realizado nuevas proyeccionesque disminuyen significativamentesu población futura. De esta suerte, en vez de tener 21.5 millones de personas en 1995 según anteriores proyecciones, se estima que en este año tiene 17.1 millones, esto es, 4.4 millones menos que lo previsto en los ochenta. Esta cifra coincide exactamente con los 17.1 millones del conteo de población de 1995 (véase el cuadro 1). Las actuales proyecciones calculan que en el año 2000 el AMCM tendrá 18 millones de habitantes y 19.6 en el 2010. En el primer año $51.7 \%$ se encontrará en los municipios conurbados del Estado de México y en el segundo 53.1 por ciento (véase el cuadro 5). En la actualidad se tiene, por ende, que desde el punto de vista demográfico y económico el AMCM se distribuye en dos entidades federativas, 


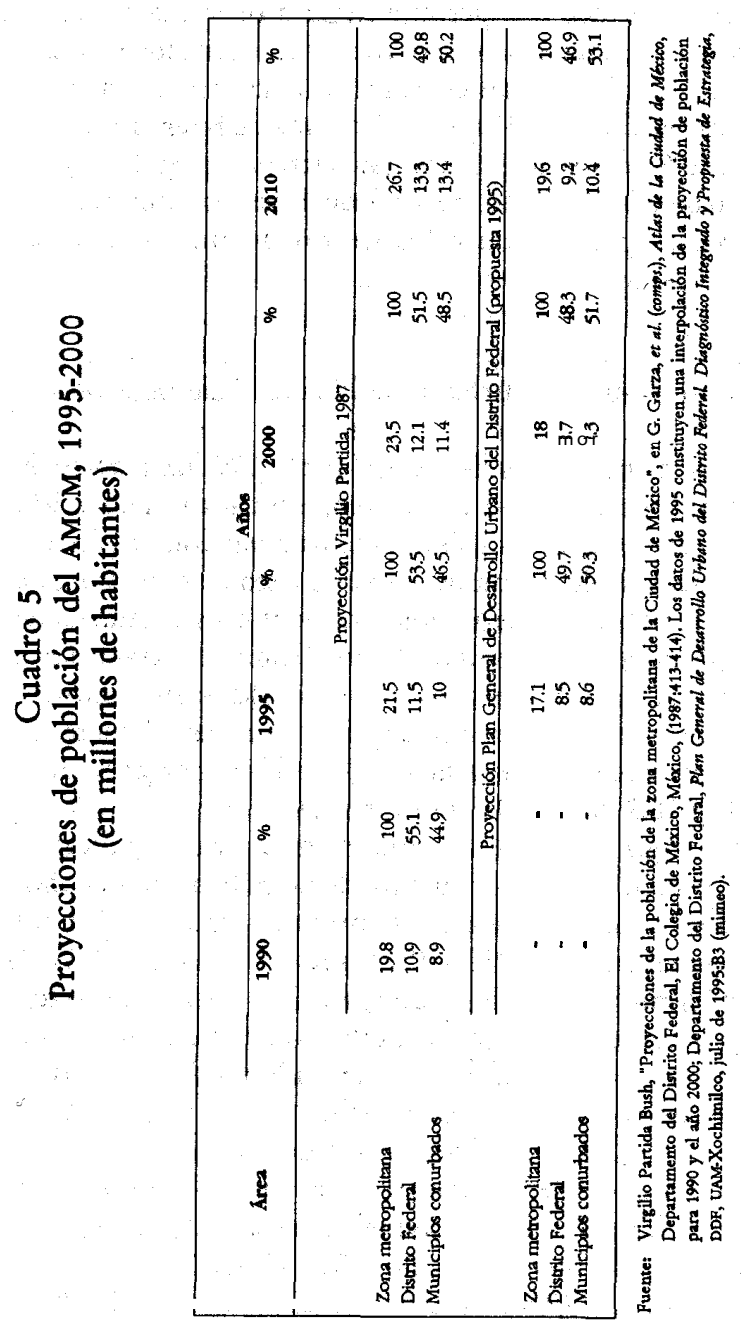

siendo cada vez más importante la parte comprendida en los municipios mexiquenses.

Todo el enjambre de leyes, programas, reglamentos, acuerdos y normas que en materia urbanística existen en el Distrito Federal y que se han presentado en la sección anterior, es en cierto sentido una realidad virtual, pues en 1995 únicamente se aplica a $\mathbf{3 9 . 8 \%}$ de los habitantes de la urbe en su conjunto ${ }^{6}$.

Por supuesto que para la mayor parte del resto de la población se aplica la normatividad urbanística existente en los municipios del Estado de México, pero ante los innumerables problemas prácticos y técnicos que surgen de la coexistencia de dos complejos cuerpos normativos que rigen el desarrollo urbano de dos partes de una misma ciudad, se deriva la conveniencia de uniformar ambos sistemas de legislación urbana.

Aun al interior del Distrito Federal, el carácter virtual de la normatividad se extiende a los 36 poblados localizados en el Área de Conservación Ecológica, principalmente de las delegaciones de Xochimilco, Tlalpan, Alvaro Obregón, Contreras y Cuajimalpa. En estos poblados ocurre una "urbanización no virtual", esto es, que tiene una existencia real pero no existe en los planos urbanos oficiales ni se ajusta a las normas vigentes.

El elevado número de leyes, reglamentos, acuerdos, programas y normas urbanísticas conduce a que todo este conjunto de instrumentos jurídicos, amalgamados con los de orden ejecutivo, legislativo y judicial puedan considerarse también de aplicación virtual siguiendo otra acepción del adjetivo, que se refiere a las cosas que son posibles, pero no tienen efecto actual.

La dimensión virtual de la normatividad urbanística alcanza incluso al interior del aparato administrativo del Distrito Federal. Por ejemplo, El Programa General de Desarrollo Urbano del Distrito Federal, 1987-1988, señala que la "vigencia de este Programa será de dos años, cuando de acuerdo con la Ley de Desarrollo Urbano del Distrito Federal, deberá revisarse [...." (DDF, 1987:11). Sin embargo, hasta fines de $\mathbf{1 9 9 4}$ no se había revisado, esto es, durante toda la administración del sexenio 1988-1994 no se realizó ninguna modificación al mismo.

- Esta cifra se calcula considerando 49.7\% de la población del AMCM en 1995 que tiene el Distrito Federal, reduciéndole $23 \%$ que se estima se encuentra en situación de irregularidad en cuanto a tenencia de la tierra. La acepción del adjetivo virtual aqui utilizada se refiere a las cosas que tienen una existencia aparente, pero no red. 
Durante 1995, primer año de la nueva administración que gobernará hasta 1997, cuando se lleven a cabo las elecciones directas del Regente del Distrito Federal, se inició la revisión del Programa General y de la Ley de Desarrollo Urbano, cuyas modificaciones se aprobaron en 1996, como se vio anteriormente.

En el siglo XXI la Ciudad de México se consolidará como el centro de una vasta región urbana polinuclear o megalópolis, que requerirá una normatividad urbanística funcional. Es preciso, por ende, establecer desde ahora los mecanismos técnicos y administrativos necesarios para diseñar un código urbano unificado a nivel metropolitano que garantice el crecimiento sustentable de sus actividades económicas y población.

\section{Bibliografía}

Asamblea de Representantes del Distrito Federal (1995), "Ley de Participación Ciudadana del Distrito Federal ${ }^{\mathrm{n}}$, en Asamblea, Órgano de Difusión, vol. 1, núm. 5, México, junio (Suplemento Legislativo).

Departamento del Distrito Federal (1972), "Ley sobre el régimen de Propiedad en Condominio de Inmuebies para el Distrito y Territorios Federales ${ }^{\mathrm{n}}$, Diario Oficial, México (28 de diciembre; modificaciones: 9 de marzo de 1986).

(1987), Programa General de Desarrollo Urbano del Distrito Federal, 1987-1988, Dirección General de Reordenación Urbana y Protección Ecológica, México.

(1994), Estatuto de Gobierno del Distrito Federal, Gaceta Oficial del Departamento del Distrito Federal, sexta época, núm. 270 , tomo $\mathrm{m}$, México (10 de agosto)

(1995), Plan General de Desarrollo Urbano del Distrito Federal. Diagnóstico Integrado y Propuesta de Estrategia, Secretaría de Desarrollo Urbano y Vivienda, Universidad Autónoma Metropolitana-Xochimilco, México, julio (mimeo).

(1996), Programa general de desarrollo urbano del Distrito Federal, 1996, México, abril.

et al., (1996), Programa para mejorar la calidad del aire en el Valle de México, 1995-2000, Departamento del Distrito Federal, Gobierno del Estado de México, Secretaría de Medio Ambiente, Recursos Naturales y Pesca, Secretaría de Salud, México (segunda reimpresión, marzo).

Diario Oficial de la Federación (1954), Reglamento de la Zona de Urbanización de los Ejidos, México (25 de mayo).

(1976), Ley de Desarrollo Urbano del Distrito Federal, México (7 de enero; modificaciones: 28 de diciembre de 1987 y 4 de enero de 1991)

(1978), Ley Orgánica del Departamento del Distrito Federal, México (29 de diciembre; modificaciones: 16 de diciembre de 1983).

(1980), Ley de Notariado para el Distrito Federal, México (8 de enero; modificaciones: 13 de enero de 1986).

(1982), Programa de Ordenación de la Zona Conurbada del Centro del País, México (2 de diciembre).

(1982), Reglamento de anuncios para el Distrito Federal, México (20 de abril).

(1982), Reglamento de Zonificación del Distrito Federal México (20 de abril; modificaciones: 3 de julio de 1987).

(1982), Usos y destinos para el área de conservación ecológica, México (29 de noviembre; modificaciones: 16 de julio de 1987).

(1983), Acuerdo por el que se declara prioritaria la regularización de la tenencia de la tiema en el Distrito Federal y la creación de reservas territoriales, México (27 de julio).

(1984), Acuerdo por el que se crea la Comisión de Limites del Distrito Federal, que tendrá como objeto auxiliar a las autoridades del Departamento del Distrito Federal en la salvaguarda del territorio propio del Distrito Federal, México (23 de mayo; modificaciones: 22 de noviembre de 1985). 
(1986), Reglamento para el uso y preservación del Bosque de Chapultepec, México (14 de agosto).

(1987), Acuerdo por el que se aprueba la nueva versión del Programa General del Programa Director de Desarrollo Urbano para el Distrito Federal, México (16 de julio).

(1987), Acuerdo por el que se aprueba la versión 1987 de los Programas Parciales de los Poblados Localizados en el Area de Conservación Ecológica de las Delegaciones del Distrito Federal, México (16 de julio; modificaciones: 5 de junio de 1988).

(1987), Acuerdo por el que se aprueba la versión 1987 de los Programas Parciales de Desarrollo Urbano de las 16 Delegaciones del Distrito Federal, México (16 de julio; modificaciones: 14 de junio de 1988 y 23 de marzo de 1993, esta última respecto a la Delegación Alvaro Obregón).

(1987), Normas técnicas complementarias para el área de conservación ecológica del Distrito Federal, México (16 de julio).

(1987), Normas técnicas complementarias para el Úrea urbana del Distrito Federal, México (16 de julio; modificaciones: 21 de diciembre de 1989).

(1987), Programa de Áreas Verdes, México (16 de julio).

(1987), Programa de Desechos Sólidos, México (16 de julio).

(1987), Programa de Equipamiento Urbano, México (16 de julio).

(1987), Programa de Infraestructura, México (16 de julio).

(1987), Programa de Medio Ambiente, México (16 de julio).

(1987), Programa de Mejoramiento del Centro Histórico, México (16 de julio).
(1987), Programa de Poblados en el Área de Preservación Ecológica, México (16 de julio; modificaciones: 5 de junio de 1988).

(1987), Programa de Prevención y Mitigación de Daños en Casos de Desastre, México (16 de julio).

(1987), Programa de Reordenación de Barrios, México (16 de julio).

(1987), Programa de Reordenución Industrial, México (16 de julio).

(1987), Programa de Reserva Territorial, México (16 de julio).

(1987), Programa de Salvaguarda de Sitios Patrimoniales, México (16 de julio).

(1987), Programa de Vialidad y Transporte, México (16 de julio).

(1987), Programa de Vivienda, México (16 de julio).

(1987), Programa para el Cinturón Verde de la Ciudad de México, México (16 de julio).

(1987), Programa Parcial de Desarrollo Urbdno. Delegación Cuaubtémoc (Versión Abreviada), México (16 de julio).

(1987), Programa Parcial de Desarrollo Urbano de la Delegación Alvaro Obregón, México (16 de julio; modificaciqnes: 14 de junio de 1988 y 23 de marzo de 1993).

(1987), Programa Parcial. de Desarrollo Urbano de la DelegaciónAzcapotzalco, México (16de julio;modificaciones: 14 de junio de 1988).

(1987), Programa Parcial de Desarrollo Urbano de la Delegación Benito Juárez, México (16 de julio; modificaciones: 14 de junio de 1988). 
- (1987), Programa Parcial de Desarrollo Urbano de la "Delegación Coyoacán, México (16 de julio; modificaciones: 14 de junio de 1988)

(1987), Programa Parcial de Desarrollo Urbano de la Delegación Cuajimalpa, México (16 de julio; modificaciones: 14 de junio de 1988).

(1987), Programa Parcial de Desarrollo Urbano de la Delegación Cuaubtémoc, México (16 de julio; modificaciones: 14 de junio de 1988)

(1987), Programa Parcial de Desarrollo Urbano de la Delegación Gustavo A. Madero, México (16 de julio; modificaciones: 14 de junio de 1988).

(1987), Programa Parcial de Desarrollo Urbano de la Delegación Iztacalco, México (16 de julio; modificaciones: 14 de junio de 1988).

(1987), Programa Parcial de Desarrollo Urbano de la Delegación Iztapalapa, México (16 de julio; modificaciones: 14 de junio de 1988).

(1987), Programa Parcial de Desarrollo Urbano de la Delegación Magdalena Contreras, México (16 de julio; modificaciones: 14 de junio de 1988).

(1987), Programa Parcial de Desarrollo Urbano de la Delegación Miguel Hidalgo, México (16 de julio modificaciones: 14 de junio de 1988).

(1987), Programa Parcial de Desarrollo Urbano de la Delegación Milpa Alta, México (16 de julio; modificaciones: 14 de junio de 1988)

(1987), Programa Parcial de Desarrollo Urbano de la Delegación Tlábuac, México (16 de julio; modificaciones: 14 de junio de 1988).
1987), Programa Parcial de Desarrollo Urbano de la Delegación Tlalpan, México (16 de julio; modificaciones: 14 de junio de 1988).

(1987), Programa Parcial de Desarrollo Urbano de la Delegación Venustiano Carranza, México (16 de julio; modificaciones: 14 de junio de 1988).

(1987), Programa Parcial de Desarrollo Urbano de la Delegación Xochimilco, México (16 de julio; modificaciones: 14 de junio de 1988).

(1987), Reglamento para el uso y preservación del Bosque de San Juan de Aragón, México (29 de abril).

(1987), Reglamento para el uso y preservación del Parque de las Águilas, México (11 de junio).

(1988), Acuerdo por el que se establece que los conjuntos babitacionales construidos por el Fideicomiso de Viviendu, Desarrollo Social y Urbano del Distrito Federal, así como las acciones de regeneración urbana y sustitución de vecindades, se sujetarán a las disposiciones contenidas en el mismo, México (23 de marzo).

(1988); Acuerdo que contiene disposiciones a las que se sujetarán los conjuntos babitacionales construidos y en proceso de construcción por el Fideicomiso de Vivienda, Desarrollo Social y Urbano del Departamento del Distrito Federal, México (29 de julio).

(1988), Establecimiento de 31 Zonas Especiales de Desarrollo Controlado, México (14 de julio).

(1988), Ley General de Equilibrio Ecológico y Protección al Ambiente, México (28 de enero).

(1988), Reglamento de la Ley General de Equilibrio Ecológico y Protección el Ambiente en materia de impacto ambiental, México (7 de junio). 
(1988), Reglamento de la Ley General de Equilibrio Ecológico y Protección el Ambiente en materia de residuos peligrosos, México (25 de noviembre).

(1988), Reglamento de la Ley General de Equilibrio Ecológico y Protección el Ambiente en materia previsión y control de la contaminación generada por vehículos automotores que circulan por el Distrito Federal y los municipios de la zona conurbada, México (25 de noviembre).

(1988), Reglamento de la Ley General de Equilibrio Ecológico y Protección el Ambiente en materia de previsión y control de la contaminación de la atmósfera, México (25 de noviembre).

(1988), Reglamento para el uso y preservación del Parque Cultural y Recreativo Desierto de los Leones, México (18 de agosto).

(1989), Acuerdo por el que se crean la Oficinas Centrales de Gestión para Licencias de Construcción y Documentos del Distrito Federal en el Colegio de Arquitectos de México A.C. y en el Colegio de Ingenieros Civiles de México A.C., México (21 de septiembre).

(1989), Acuerdo por el que se delega a los titulares de las Delegaciones del Distrito Federal, la facultad de otorgar y expedir las licencias de usos de suelo en el área urbana dentro de sus respectivas jurisdicciones, México (21 de septiembre).

(1989), Acuerdo referente a los Programas de Regulación Territorial que se lleven a cabo por el Distrito Federal o sus entidades sectoriales, México (5 de abril).

(1989), Reglamento de cementerios del Distrito Federal, México (28 de diciembre).

(1989), Reglamento para el servicio de limpia del Distrito Federal, México (27 de julio).

(1989), Tabla de usos de suelo, México (21 de septiembre; modificaciones: 29 de julio de 1991).
(1989), México (21 de septiembre).

(1990), Acuerdo por el que se crea el Consejo para el Mejoramiento de la Imagen Urbana del Distrito Federal, órgano de consulta y asesoramiento del Jefe del Departamento del Distrito Federal en asuntos relacionados con la definición de políticas de elaboración, ejecución y evialuación de programas concernientesal mejoramiento estético de la ciudad, México (28 de febrero).

(1990), Acuerdo por el que se crea el Consejo Asesor para la Ejecución del Programa de Rescate Ecológico de Xocbimilco, México (28 de febrero).

(1990), Reglamento para la atención de los minúsvalidosen el Distrito Federal, México (16 de febrero).

(1991), Acuerdo por el que con objeto de apoyar la vivienda de interés social se eximirá tomando en cuenta el tipo de construcción de que se trate, de parte o de la totalidad de los estacionamientos en el Distrito Federal, México (8 de abril).

(1991), Acuerdo por el que se determina que los usos de suelo que se encuentran permitidos $\boldsymbol{m}$ las Zonas Especiales de Desarrollo Controlado y que no cuenten con un Programa de Mejoramiento, no se les aplique la denominación de condicionados en el Distrito Federal, México (10 de enero).

(1991), Acuerdo que complementa la tabla de usos de suelo pava la intensidad de construcciones de oficinas de gobierno y privadas en el Distrito Federal, México (29 de julio; modificaciones: 24 de diciembre de 1991).

(1991), Reglamento de Estacionamientos Públicos, México $(27$ de mayo).

(1992), Acuerdo por el que se aprueba la versión 1992 del Programa Parcial de Desarrollo Urbano de la Delegación Xocbimilco, así como la versión abreviada del citado acuerdo, México (16 de noviembre).

(1993), Ley de Seguridad Pública, México (19 de julio). 
(1993), Reglamento de Construcciones del Distrito Federal, México (2 de agosto).

(1993), Reglamento del servicio de agua y drenaje del Distrito Federal, México (6 de agosto).

(1993), Reglamento para la protección de los nofumadores del Distrito Federal, México (2 de agosto).

Gamboa de Buen, Jorge (1994), Ciudad de México, una visión, México, FCE.

Garza, Gustavo (1986), “Planeación urbana en México en periodo de crisis (1983-1984)”, en Estudios Demográficos y Urbanos, vol. 1, núm. 1, enero-abril, México, El Colegio de México.

(1991), "Dinámica industrial de la Ciudad de México, 19401988", en Estudios Demográficos y Urbanos, vol. 6, núm. 1, enero-abril, México, El Colegio de México.

y Fernando Aragón (1995), "La contaminación atmosférica de la ciudad de México a escala megalopolitana", en Estudios Demográficos y Urbanos, vol. 10, núm. 1, enero-abril, México, El Colegio de México.

Gobierno Constitucional de los Estados Unidos Mexicanos, et al. (1983), Programa de Desarrollo de la Zona Metropolitana de la Ciudad de México y de la Región Centro, México, octubre.

Hiernaux, Daniel (1989), "La planeación de la Ciudad de México: logros y contradicciones", en Gustavo Garza (comp.), Una década de planeación urbano-regional en México, 1978-1988, México, El Colegio de México.

INEGI (1986), x Censo General de Población y Vivienda, INEGI, México.

(1970), IX Censo General de Población y Vivienda, INEGI, México.

(1990), XI Censo General de Población y Vivienda, INEGI, México.
(1994), Anuario Estadístico del Distrito Federal, INEGI, México.

Legorreta, Jorge (1992), "Expansión urbana de la Ciudad de México", en A. Bassols, J. Delgadillo y F. Torres (comp.), E desarrollo regional en México: Teoría y práctica, México, Instituto de Investigaciones Económicas, UNAM.

Partida Bush, Virgilio (1987), "Proyecciones de la población de la zona metropolitana de la Ciudad de México", en G. Garza, et al. (comps.), Atlas de la Ciudad de México, DDF, El Colegio de México, México.

Secretariado Técnico Intergubernamental (1990), Programa Integral contra la contaminaciónAtmosférica de la Zona Metropolitana de la Ciudad de México, México, octubre. 